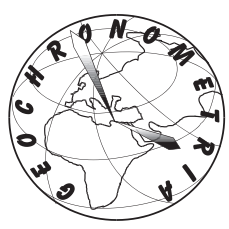

\title{
INFRARED RADIOFLUORESCENCE (IR-RF) OF K-FELDSPAR: AN INTERLABORATORY COMPARISON
}

\author{
MADHAV K. MURARI ${ }^{1,2, *}$, SEBASTIAN KREUTZER ${ }^{3,4}$, MARINE FROUIN $^{5,6}$, JOHANNES FRIEDRICH $^{7}$, TOBIAS LAUER $^{8}$, \\ NICOLE KLASEN ${ }^{9}$, CHRISTOPH SCHMIDT ${ }^{7,10}$, SUMIKO TSUKAMOTO ${ }^{11}$, DANIEL RICHTER ${ }^{8,12}$, NORBERT MERCIER ${ }^{4}$, MARKUS FUCHS ${ }^{2}$ \\ ${ }^{1}$ Geochronology Group, Inter-University Accelerator Centre, New Delhi, India \\ ${ }^{2}$ Department of Geography, Justus Liebig University Giessen, Giessen, Germany \\ ${ }^{3}$ Department of Geography and Earth Sciences, Aberystwyth University, Aberystwyth, Wales, United Kingdom \\ ${ }^{4}$ IRAMAT-CRP2A, UMR 5060, CNRS-Université Bordeaux Montaigne, Pessac, France \\ ${ }^{5}$ Department of Geosciences, Stony Brook University, Stony Brook, NY, United States \\ ${ }^{6}$ Research Laboratory for Archaeology and the History of Art, Oxford University, Oxford, United Kingdom \\ ${ }^{7}$ Chair of Geomorphology, University of Bayreuth, Bayreuth, Germany \\ ${ }^{8}$ Department of Human Evolution, Max Planck Institute for Evolutionary Anthropology, Leipzig, Germany \\ ${ }^{9}$ Federal Office for Radiation Protection, Berlin, Germany \\ ${ }^{10}$ Institute of Earth Surface Dynamics, University of Lausanne, Lausanne, Switzerland \\ ${ }^{11}$ Leibniz Institute for Applied Geophysics, Hannover, Germany \\ ${ }^{12}$ Freiberg Instruments $\mathrm{GmbH}$, Freiberg, Germany
}

Received 28 February, 2021 Accepted 06 September, 2021

\begin{abstract}
Infrared Radiofluorescence (IR-RF) is a relatively new method for dosimetric dating of the depositional timing of sediments. This contribution presents an interlaboratory comparison of IR-RF measurements of sedimentary feldspar from eight laboratories. A comparison of the variability of instrumental background, bleaching, saturation, and initial rise behaviour of the IR-RF signal was carried out. Two endmember samples, a naturally bleached modern dune sand sample with a zero dose and a naturally saturated sample from a Triassic sandstone ( $250 \mathrm{Ma})$, were used for this interlaboratory comparison. The major findings of this study are that (1) the observed IR-RF signal keeps decreasing beyond $4000 \mathrm{~Gy}$, (2) the saturated sample gives an apparent palaeodose of $1265 \pm 329 \mathrm{~Gy}$ and (3) in most cases, the natural IR-RF signal of the modern analogue sample (resulting from natural bleaching) is higher than the signal from laboratory-induced bleaching of $6 \mathrm{~h}$, using a solar simulator (SLS). In other words, the laboratory sample bleaching was unable to achieve the level of natural bleaching. The results of the investigations are discussed in detail, along with possible explanations.
\end{abstract}

Keywords

IR-RF, interlaboratory-comparison, K-feldspar, dosimetry, dating

\section{INTRODUCTION}

Unlike conventional luminescence dating methods using thermoluminescence (TL) and optically stimulated luminescence (OSL) (cf. Aitken, 1985, 1998), where the signals of interest relate to complex recombination pathways, model-based studies believe that the infrared radiofluorescence (IR-RF) signal provides a direct measure of the fraction of empty electron traps (Trautmann et al., 1999a, b, 2000). The IR-RF signal intensity decays with increasing dose and is used for dosimetry and dating. Trautmann et al. (1998) characterised radioluminescence signals (emissions stimulated by ionising radiation) from various feldspar specimens to investigate their potential for dating applications. They reported that microcline and orthoclase (potassium-rich feldspar) had a dose-dependent signal with

Corresponding author: Madhav K. Murari

e-mail: madhav.murari@iuac.res.in

ISSN 1897-1695 (online), 1733-8387 (print)

(C) 2021 M. K. Murari et al. This work is licensed under the Creative Commons Attribution-NonCommercial-NoDerivatives 3.0 License. 
their emission centred at $\sim 854 \mathrm{~nm}(1.45 \mathrm{eV})$. Later, Schilles (2002), Erfurt (2003a) and Erfurt and Krbetschek (2003b) reported the peak emission to occur at $\sim 865 \mathrm{~nm}(1.43 \mathrm{eV})$. Erfurt and Krbetschek (2003a) proposed the term IR-RF instead of radioluminescence (cf. Murari et al., 2021).

The literature offers divergent views on the applicability of IR-RF as a dating method. IR-RF as a potential dating method was explored with home-made systems, for example, by Trautmann et al. (1998), Krbetschek et al. (2000), Schilles (2002) and Erfurt (2003a, b), as well as with commercial systems from Risø and Freiberg Instruments (Lapp et al., 2012; Richter et al., 2013) by Buylaert et al. (2012) and Frouin et al. (2015), respectively. Buylaert et al. (2012) recognised problems with this dating method, in particular (1) an overestimation of ages by $15 \%$ for younger samples (20-45 ka) and (2) an underestimation in ages up to $30 \%$ for older samples $(\sim 130 \mathrm{ka})$. Frouin et al. $(2015,2017)$ used a Freiberg Instruments lexsyg research system to demonstrate that the IR-RF signal fulfils the basic requirements of luminescence dating methods, e.g., signal bleachability, thermal stability and dose dependency. Recent methodological work on the optical resetting of the IR-RF signal and modified protocols for dose estimation yielded promising results (Frouin et al., 2015; Huot et al., 2015; Frouin et al., 2017; Kreutzer et al., 2017b; Kreutzer et al., 2018; Murari et al., 2018). Such observations and the recent progress towards IR-RF as a dating method demand further research on fundamental aspects such as signal resetting and the accessible dose range, as well as assessing the reproducibility of commercial devices. Both were achieved in this investigation by means of an interlaboratory comparison.

The present study follows the $\mathrm{RF}_{70}$ protocol introduced by Frouin et al. (2017), a variant of the infrared radiofluorescence single-aliquot regeneration (IRSAR) protocol developed by Erfurt and Krbetschek (2003a). In this protocol, signal bleaching and stimulation are applied at an elevated temperature $\left(70{ }^{\circ} \mathrm{C}\right.$, Table 4). The measurement conditions were kept identical, e.g. the same detection window using comparable filter combinations, and the bleaching power of individual devices was normalized following the settings given by Frouin et al. (2015). Further, two reference samples were used for this study and distributed to all laboratories after testing the IR-RF dose recovery characteristics and the purity of the K-feldspar samples using Scanning Electron Microscopy with an Energy Dispersive X-ray (SEM-EDX).

This interlaboratory comparison was established to explore the following questions related to IR-RF:

1. To which extent does the IR-RF signal bleach in the laboratory compared to a naturally bleached modern analogue sample?
2. What is the potential upper dating limit of the IR-RF method?

3. How reproducible are the commercial instruments, and what is their range of variability?

4. Does an initial IR-RF signal rise exist for each device and both reference samples?

Eight laboratories participated in this comparative study. Measurements were carried out on seven lexsyg research devices from Freiberg Instruments (Freiberg, Germany) and one Risø TL-OSL device from the Center for Nuclear Technologies, DTU Risø (Roskilde, Denmark). The differences in the results among all machines are explored and discussed in detail.

\section{INSTRUMENT CONFIGURATION AND SETTING}

The seven lexsyg research devices provided a comparison amongst readers from the same manufacturer, while the device from Risø allowed assessing the differences between the luminescence readers from two different manufacturers. Some parameters cannot be kept identical even for devices from the same manufacturer, e.g., the dose rate of the radiation source and the power of the solar simulator system (SLS) LEDs varies slightly from one device to another (Lapp et al., 2012; Richter et al., 2012, 2013). In the present study, for the lexsyg research devices, the dose rate values averaged to $\sim 0.059 \pm 0.001 \mathrm{~Gy} \cdot \mathrm{s}^{-1}$ (Table 1). The SLS power varied between devices such that even though the peak wavelength for each array of LEDs was similar, the maximum possible power for each LED array varied. Therefore, the total energy flux was variable amongst the devices. In Frouin et al. (2017), 3 h of SLS bleaching is recommended, followed by a $1 \mathrm{~h}$ pause. In the present study, each SLS bleaching time was fixed to the total bleaching energy equivalent to $6 \mathrm{~h}$ of SLS bleaching with the device used by Frouin et al. (2015), followed by a $2 \mathrm{~h}$ pause. In the Risø device, a bleaching time of $1500 \mathrm{~s}$ using a ultraviolet-light emitting diode (UV-LED) within a Risø TL/OSL DA-20 reader was used after Buylaert et al. (2012).

The Risø device has a few technical differences compared to the lexsyg research device, e.g., the radiation source is not a ring-type module as in the lexsyg research (Richter et al., 2012). Therefore, IR-RF signal detection is facilitated through an optical light guide (Lapp et al., 2012), which reduces the amount of signal from the sample compared to the lexsyg research devices. On the other hand, in the Risø device, the photomultiplier tube (PMT) does not sit directly above the beta source, resulting in a lower background signal. The dose rate of the radiation source for the Risø device is $0.119 \pm 0.006 \mathrm{~Gy} \cdot \mathrm{s}^{-1}$. Furthermore, 
Table 1. Device parameters used for the interlaboratory comparison measurements.

\begin{tabular}{|c|c|c|c|c|c|c|c|}
\hline Laboratory & $\begin{array}{c}\text { Device } \\
\text { [manufacturing year] }\end{array}$ & PMT & Filter & $\begin{array}{c}\text { Source dose rate } \\
{\left[\mathrm{Gy} \cdot \mathrm{s}^{-1}\right]}\end{array}$ & Calibration date & $\begin{array}{l}\text { Bleaching power } \\
\text { density }\left[\mathrm{mW} \cdot \mathrm{cm}^{-2}\right]\end{array}$ & $\begin{array}{c}\text { Bleaching } \\
\text { time [h] }\end{array}$ \\
\hline Bordeaux & Lexsyg [2012] & $\mathrm{H} 7421-50$ & D850/40 & $0.065 \pm 0.006$ & 04.04 .2015 & 375 & 6.00 \\
\hline Bayreuth & Lexsyg [2011] & $\mathrm{H} 7421-50$ & HC857/30* & $0.051 \pm 0.002$ & 18.08 .2016 & 313 & 7.20 \\
\hline Freiberg & Lexsyg [2013] & $\mathrm{H} 7421-50$ & D850/40 & $0.055 \pm 0.003$ & 07.10 .2014 & 208 & 10.80 \\
\hline Giessen & Lexsyg [2013] & $\mathrm{H} 7421-50$ & $\mathrm{D} 850 / 40$ & $0.066 \pm 0.002$ & 01.02 .2016 & 326 & 6.89 \\
\hline Köln & Lexsyg [2011] & $\mathrm{H} 7421-50$ & D850/40 & $0.053 \pm 0.005$ & 27.08 .2015 & 326 & 6.90 \\
\hline Leipzig & Lexsyg [2014] & $\mathrm{H} 7421-50$ & $\mathrm{D} 850 / 40$ & $0.058 \pm 0.004$ & 01.08 .2016 & 228 & 9.86 \\
\hline Oxford & Lexsyg [2014] & $\mathrm{H} 7421-50$ & D850/40 & $0.057 \pm 0.003$ & 27.11.2017 & 293 & 7.67 \\
\hline Hannover & $\operatorname{Ris} \varnothing$ [2017] & $\mathrm{H} 7421-50$ & D900/100* & $0.116 \pm 0.006$ & 01.10 .2020 & $1000^{\#}$ & $0.42^{\#}$ \\
\hline
\end{tabular}

*Filters used for the devices at Bayreuth and Hannover have slightly different bandpass for IR-RF measurement.

\#The Ris $\varnothing$ device has a UV-LED bleaching unit, therefore the bleaching time was set to 1500 s after Buylaert et al. (2012)

Table 2. Solar simulator spectra settings for each LED normalized to the Bordeaux solar simulator settings.

\begin{tabular}{|c|c|c|c|c|c|c|c|}
\hline $\begin{array}{l}\text { LEDs wavelength } \\
\text { [nm] }\end{array}$ & $\begin{array}{c}\text { Bordeaux } \\
{\left[\mathrm{mW} \cdot \mathrm{cm}^{-2}\right]}\end{array}$ & $\begin{array}{c}\text { Bayreuth } \\
{\left[\mathrm{mW} \cdot \mathbf{c m}^{-2}\right]}\end{array}$ & $\begin{array}{c}\text { Freiberg* } \\
{\left[\mathrm{mW} \cdot \mathrm{cm}^{-2}\right]}\end{array}$ & $\begin{array}{c}\text { Giessen } \\
{\left[\mathrm{mW} \cdot \mathrm{cm}^{-2}\right]}\end{array}$ & $\begin{array}{c}\text { Köln } \\
{\left[\mathrm{mW} \cdot \mathrm{cm}^{-2}\right]}\end{array}$ & $\begin{array}{c}\text { Leipzig } \\
{\left[\mathrm{mW} \cdot \mathrm{cm}^{-2}\right]}\end{array}$ & $\begin{array}{c}\text { Oxford } \\
{\left[\mathrm{mW} \cdot \mathrm{cm}^{-2}\right]}\end{array}$ \\
\hline 365 & 10 & 8 & 6 & 9 & 9 & 6 & 8 \\
\hline 462 & 63 & 53 & 35 & 55 & 55 & 38 & 49 \\
\hline 525 & 54 & 45 & 30 & 47 & 47 & 33 & 42 \\
\hline 590 & 37 & 31 & 21 & 32 & 32 & 23 & 29 \\
\hline 625 & 115 & 96 & 64 & 100 & 100 & 70 & 90 \\
\hline 850 & 96 & 80 & 53 & 84 & 83 & 58 & 75 \\
\hline
\end{tabular}

Note: Each solar simulator's power is normalized to the settings of the lexsyg device from Bordeaux. The bleaching time for every device is estimated using the total flux equivalent to the bleaching of six hours of the device in Bordeaux used by Frouin et al. (2015).

*The Freiberg's solar simulator has one different LED array which has its central peak wavelength at $458 \mathrm{~nm}$ instead of $462 \mathrm{~nm}$. The manufacturer quotes $\pm 5 \mathrm{~nm}$ peak width.

as mentioned above, the Risø reader uses the bleaching unit, which consists of a monochromatic UV-LED of 395$410 \mathrm{~nm}$ with an optical power of $\sim 1 \mathrm{~W}\left(\sim 700 \mathrm{~mW} \cdot \mathrm{cm}^{-2}\right.$ at the sample position; Lapp et al., 2012). The parameters of the SLS used for this study are listed in Table 2.

The IR-RF data analysis for this manuscript was carried out using the R (R Core Team 2021) package 'Luminescence' (Kreutzer et al., 2012; Kreutzer et al., 2017a).

Frouin et al. (2015) optimised the SLS settings at the Bordeaux device for a power density of $\sim 375 \mathrm{~mW} \cdot \mathrm{cm}^{-2}$ by maintaining low induced heat on the sample, and these authors suggested the use of minimal flux from UV wavelengths. Bleaching spectra for the sunlight, SLS of lexsyg research devices and the UV-LED for the Risø device are shown in Fig. 1. The parameters of the SLS settings used for this study are tabulated in Table 2, as suggested by Frouin et al. (2015). The spectra of the SLS of the lexsyg device and the sunlight were measured on 9 October 2018, using the spectrometer installed on lexsyg research at the Giessen luminescence laboratory, Germany. The spectrometer system used a Shamrock-163 spectrograph and a Newton 920 BU CCD camera manufactured by Andor, an Oxford Instruments company. An ND10B glass filter (neutral density filter, a product of Thorlabs, 2020) was used to reduce the light intensity. The normalised intensity spectra for sunlight and SLS are plotted against the wavelength in Fig. 1.

\section{SAMPLE CHARACTERISTICS}

For the present study, the IR-RF was measured on coarse grain (sand-sized) K-feldspar, extracted from a wellbleached and a geologically old sample (Table 3). The well-bleached sample LUM1225 (150-200 $\mu \mathrm{m}$, CUD 1-E in Kunz et al., 2010) from a coastal dune from Cuddalore (south-east India) was provided by the Leibniz Institute for Applied Geophysics (LIAG Hannover, Germany). Sample bleaching was confirmed by quartz OSL giving a residual dose of $0.1 \pm 0.01$ Gy (Kunz et al., 2010). The geologically 


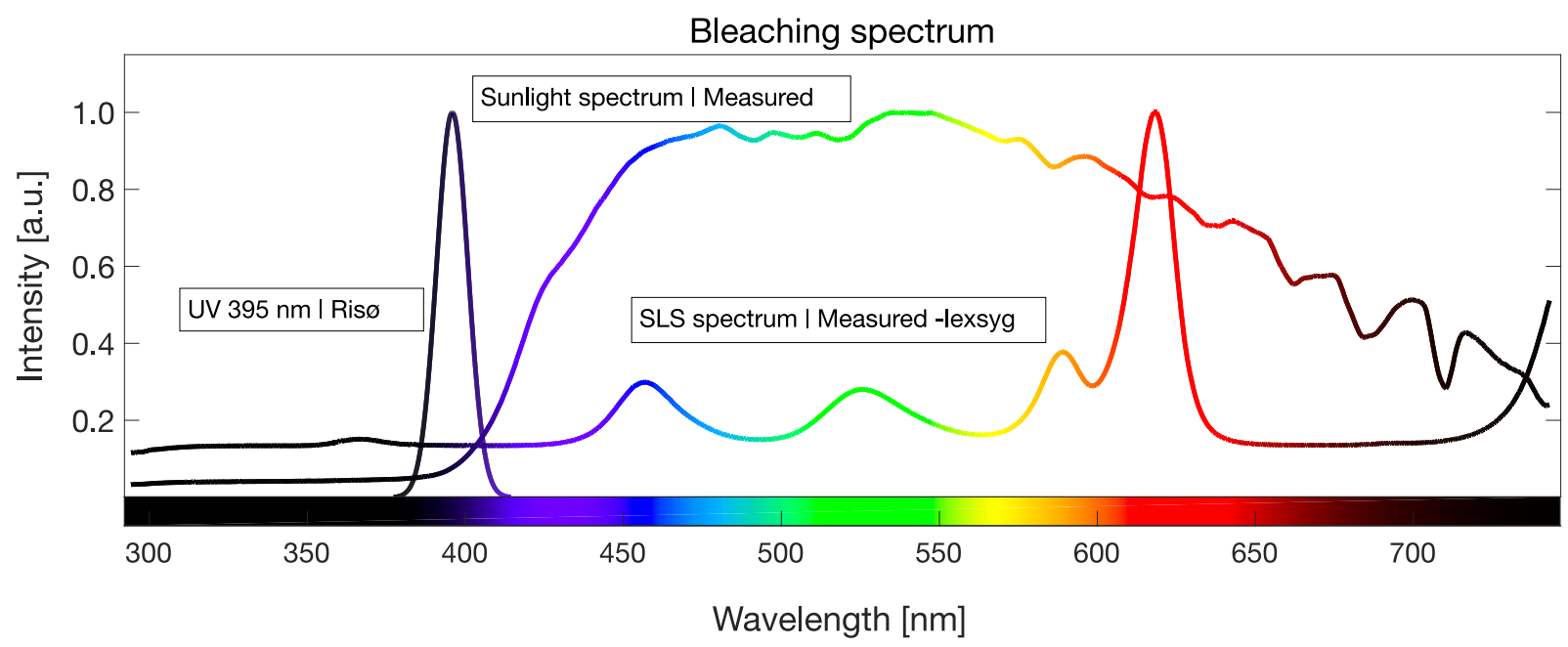

Fig 1. Spectra for sunlight and solar simulator of lexsyg at Giessen measured with the spectrometer while for Risø device, a computer-generated gaussian profile centered at $395 \mathrm{~nm}$ plotted for UV-LED $(395 \mathrm{~nm})$. The spectrometer is a combination of a spectrograph (Shamrock-163) and a CCD camera (Newton 920 BU) manufactured by Andor, an Oxford Instruments company. To facilitate easy comparison, spectra are normalized to the maximum intensity. Spectra for sunlight and solar simulator were measured with the same spectrometer settings, and light intensity was reduced using the neutral density filter ND 10B.

Table 3. Samples used for the intercomparison IR-RF measurements.

\begin{tabular}{llclcll}
\hline Sample code & Sample preparation & Grain size $[\mu \mathrm{m}]$ & Sediment type & Expected age [a] & Method & Reference \\
\hline LUM1225 & Hannover & $150-200$ & Beach dune sand & 0 & Quartz OSL dose & Kunz et al. (2010) \\
G1326 & Giessen & $160-200$ & Sandstone & $10^{8}$ & Stratigraphy & Röhling et al. (2018) \\
\hline
\end{tabular}

Note: Sample LUM1225 is GI361 in Murari et al. (2018) and CUD 1-E in Kunz et al (2010).

old sample GI326 was extracted from a Triassic sandstone near Bayreuth, Germany, with an expected age of $\sim 250 \mathrm{Ma}$ (Röhling et al., 2018), having accumulated an estimated dose of $\sim 500 \mathrm{kGy}$ (see Section 4.3). The extraction of $\mathrm{K}$-feldspar involved sampling of the light-shielded inner part of the sandstone (Herman et al., 2010), which was treated with $\mathrm{HCl}(30 \%)$ for 2 days to disaggregate the mineral grains, then following standard preparation methods for extracting the 160-200 $\mu \mathrm{m} \mathrm{K}$-feldspar grain size fraction (e.g., Preusser et al., 2008). This sample was prepared at the luminescence laboratory in Giessen, Germany (Table 3).

Scanning Electron Microscope Energy Dispersive $\mathrm{X}$-Rays (SEM-EDX) analysis was used to identify the presence of K-feldspar. The prepared sample grains were scanned to detect the abundance of K-feldspar in the sample at the SEM-EDX facility at Bordeaux, France (EOL JSM-6460LV, detector: Oxford Instruments X-Max (51-XMX0002), accelerating voltage $20 \mathrm{kV}$, beam current $55 \mu \mathrm{A}$, automated grain recognition, software: Oxford Instruments $I N C A$ version 4.11). A ternary diagram $\mathrm{Al}-\mathrm{Ca}+\mathrm{Na}-\mathrm{K}$ was used to infer the K-feldspar concentration (e.g., Nesbitt and Young, 1984), and the elemental concentration was plotted for both samples (Fig. 2). The higher concentration of $\mathrm{K}$ (mass $\%$ ) than the combined content of $\mathrm{Ca}+\mathrm{Na}(\operatorname{mass} \%)$ and $\mathrm{Al}$ suggests that the samples are dominated by K-rich feldspar grains.

To test the suitability of samples for our interlaboratory comparison, a dose-recovery experiment was carried out using the $\mathrm{RF}_{70}$ protocol (Frouin et al., 2017) at the Giessen laboratory. Prior to the dose-recovery test, both samples were bleached for $\sim 7 \mathrm{~h}$ using the SLS. A dose of $\sim 660 \mathrm{~Gy}$ ( $\sim 10,000 \mathrm{~s}$ of irradiation) was then given to the samples and determined by the vertical sliding method (Murari et al., 2018). Fig. 3 shows the dose-recovery results, and, in both cases, the given dose of $\sim 660$ Gy could be recovered within $\pm 10 \%$ uncertainty limit.

\section{EXPERIMENTS AND OBSERVATIONS}

For the interlaboratory comparison study, two sets of experiments were performed on all devices: (1) background measurement on three empty sample carriers and (2) IR$\mathrm{RF}$ measurements for natural $\left(\mathrm{RF}_{\mathrm{nat}}\right)$ and regenerated $\left(\mathrm{RF}_{\text {reg }}\right)$ signals on both samples. Bleaching was conducted 

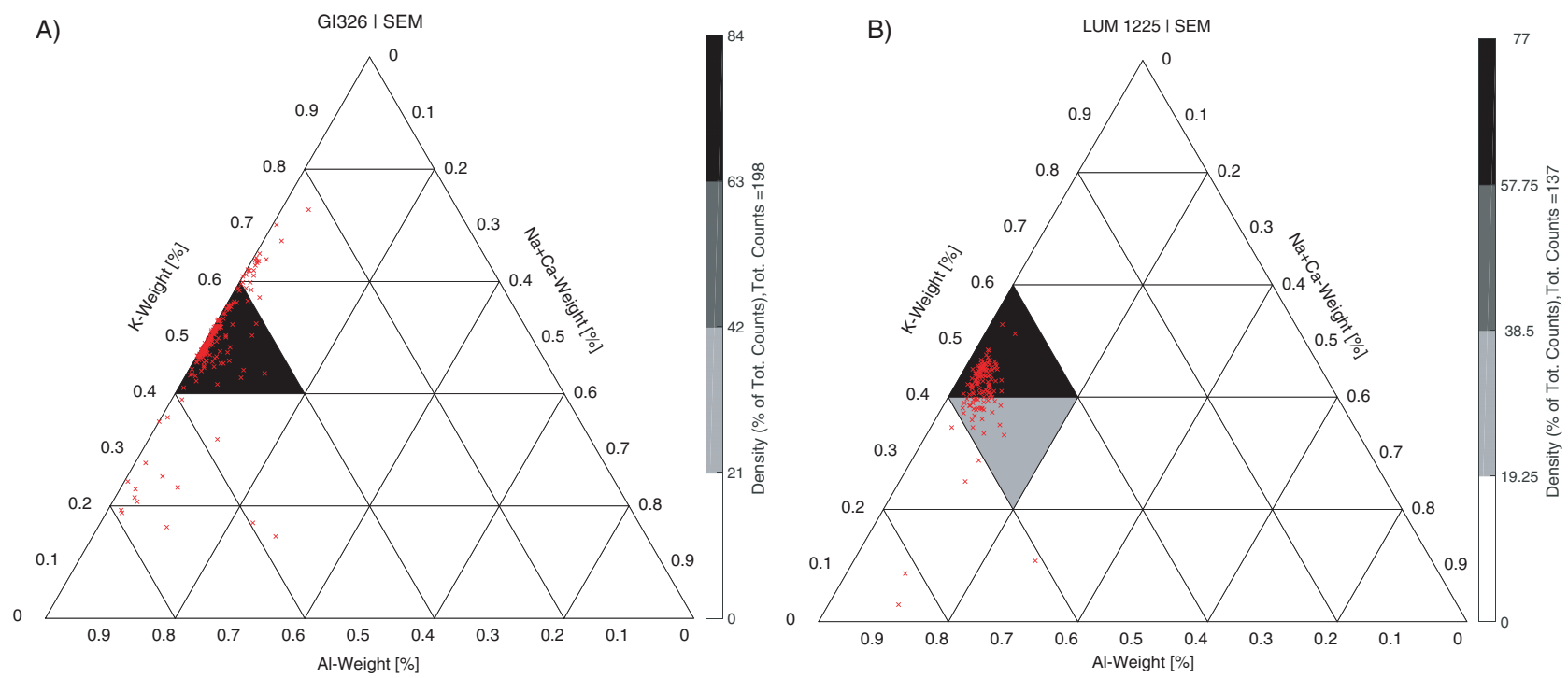

c) Close-up view for randomly selected grains
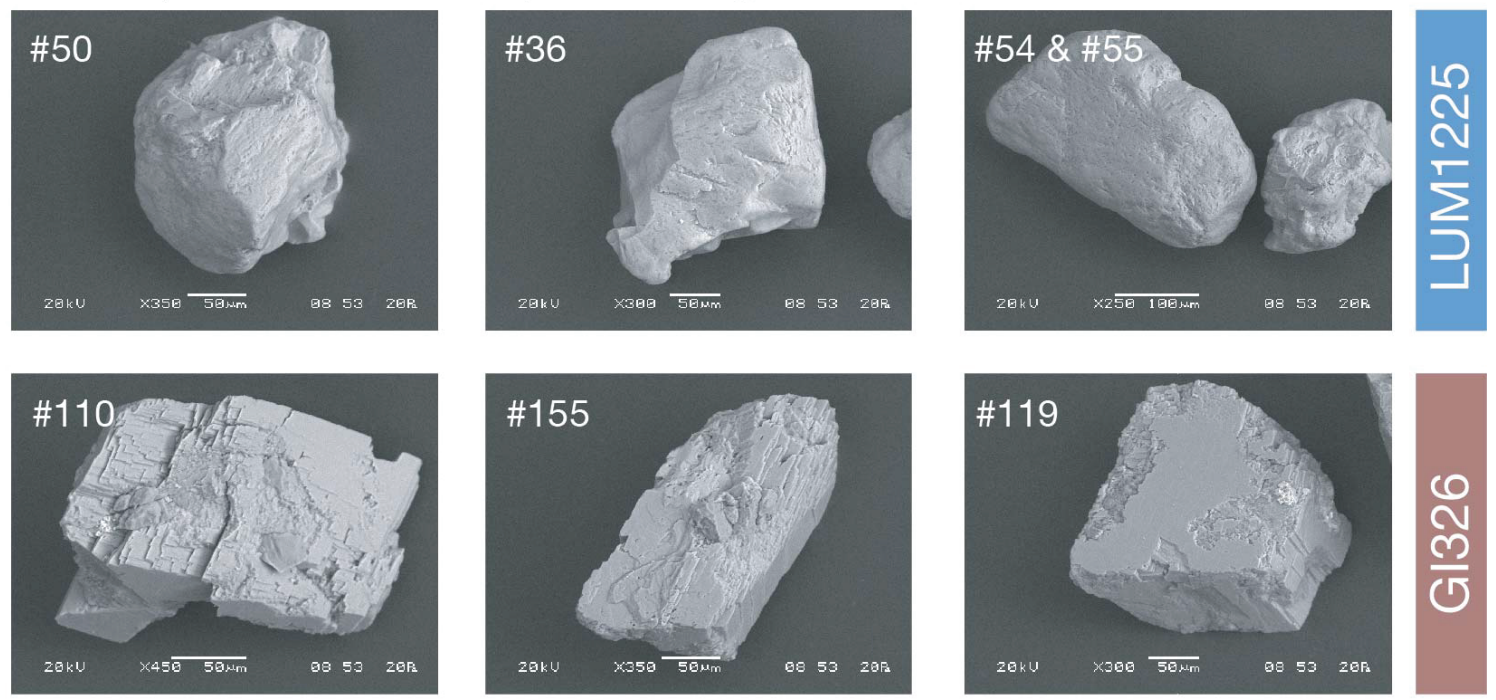

Fig 2. A) and B) are ternary diagrams for elemental concentration obtained from the SEM analysis. A total of 137 grains for sample LUM1225 and 198 grains for sample G1326 were examined. The ternary diagram shows the atomic weight percentage of potassium (K), combined calcium and so$\operatorname{dium}(\mathrm{Ca}+\mathrm{Na})$, and aluminum (Al) for each grain. Al was kept as a common element in each feldspar. C) SEM images of randomly selected grains.

using the SLS in the lexsyg research devices, and the Risø device's UV-LED. Measurement protocols are listed in Table 4.

\subsection{Background Measurement}

To check the overall reliability of the data from the individual devices, background measurements on three empty cups were carried out, following the protocol given in Table 4. In the case of IR-RF measurements, a major source of noise is the radiation source inducing bremsstrahlung. Due to the different ways of signal detection for the lexsyg research and Risø devices, the IR-RF may also have different background signals (see Section 2). It is expected that the Risø device has a reduced background signal, as the PMT is at a fair distance from the beta source (Lapp et al., 2012).

The background data is presented in a box plot in Fig. 4, showing the scatter among all devices from the different laboratories. The average background counts for the five lexsyg research devices amount to $33,932 \pm 6729 \mathrm{cts} \cdot \mathrm{s}^{-1} \cdot \mathrm{Gy}^{-1}$, excluding the Bordeaux and Leipzig devices with $6840 \pm 160 \mathrm{cts} \cdot \mathrm{s}^{-1} \cdot \mathrm{Gy}^{-1}$ and $78,020 \pm 49,265 \mathrm{cts} \cdot \mathrm{s}^{-1} \cdot \mathrm{Gy}^{-1}$, respectively. Given the age of the reader (manufacturing year 2012; installation date at the beginning of 2013), the lower background of the Bordeaux device might be caused by radiation-induced degeneration of the used filter, resulting in a significantly reduced optical 

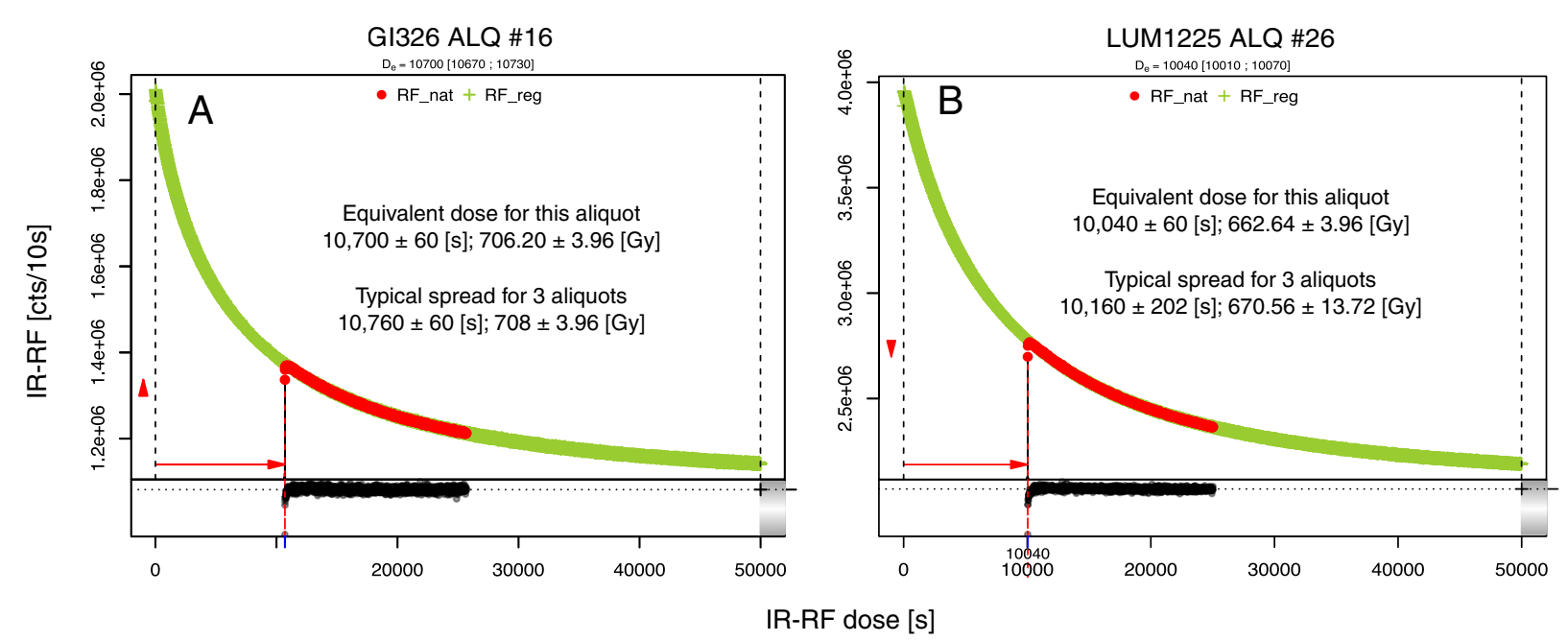

Fig 3. A) and B) show the dose recovery for a given dose of $10 \mathrm{ks}$ (660 Gy) for samples GI326 and LUM1225 measured on lexsyg research at Giessen. Dose was recovered using the vertical sliding method (Murari et al., 2018). The dose rate of used device was 0.066 Gy. $s^{-1}$ (calibrated on 01.02.2016). Each aliquot for both samples resulted in a dose recovery difference between ca $1.6 \%$ and $7.6 \%$ from unity. Both plots have same units for $x$-axes and $y$-axes.

Table 4. The applied IR-RF protocols.

\begin{tabular}{|c|c|c|}
\hline Steps & Treatment & Comment \\
\hline \#\# & Protocol for background measurement & \\
\hline 1. & Preheat $\left(70^{\circ} \mathrm{C}\right.$ for $\left.900 \mathrm{~s}\right)$ & Temperature stabilization \\
\hline 2. & $\operatorname{IR}-\mathrm{RF}\left(70^{\circ} \mathrm{C}\right.$ for $\left.1 \mathrm{ks}\right)$ & Background measurement \\
\hline \#\# & IR-RF Protocol for sample measurement & \\
\hline 1. & Preheat $\left(70^{\circ} \mathrm{C}\right.$ for $\left.900 \mathrm{~s}\right)$ & Temperature stabilization \\
\hline 2. & IR-RF (70 ${ }^{\circ} \mathrm{C}$ for $\left.10 \mathrm{ks}\right)$ & IR-RF Natural $\left(\mathrm{RF}_{\text {nat }}\right)$ \\
\hline 3. & Bleach $\left(70^{\circ} \mathrm{C} \text {, varying time }\right)^{*}$ & $8.1 \mathrm{~kJ} \cdot \mathrm{cm}^{-2}$ equivalent to Bordeaux \\
\hline 4. & Pause $(2 \mathrm{~h})$ & To avoid phosphorescence after bleach \\
\hline 5. & IR-RF (70 ${ }^{\circ} \mathrm{C}$ for $\left.65 \mathrm{ks}\right)$ & IR-RF Regenerated $\left(\mathrm{RF}_{\text {reg }}\right)$ \\
\hline \#\# & IR-RF dose recovery measurement protocol at Giessen & \\
\hline 1. & Bleaching $\left(70^{\circ} \mathrm{C}, 7 \mathrm{~h}\right)$ & $8.1 \mathrm{~kJ} \cdot \mathrm{cm}^{-2}$ equivalent to Bordeaux \\
\hline 2. & Pause $(2 \mathrm{~h})$ & To avoid phosphorescence after bleach \\
\hline 3. & Preheat $\left(70^{\circ} \mathrm{C}\right.$ for $\left.900 \mathrm{~s}\right)$ & Temperature stabilization \\
\hline 4. & IR-RF $\left(70^{\circ} \mathrm{C}\right.$ for $\left.10 \mathrm{ks}\right)$ & IR-RF dose to be recovered \\
\hline 5. & Pause $(2 \mathrm{~h})$ & - \\
\hline 6. & Preheat $\left(70^{\circ} \mathrm{C}\right.$ for $\left.900 \mathrm{~s}\right)$ & Temperature stabilization \\
\hline 7. & IR-RF $\left(70^{\circ} \mathrm{C}\right.$ for $\left.15 \mathrm{ks}\right)$ & $15 \mathrm{ks} \mathrm{IR-RF} \mathrm{signal} \mathrm{to} \mathrm{recover} \mathrm{given} \mathrm{dose} \mathrm{of} 10 \mathrm{ks}$ [step 4] \\
\hline 8. & Bleaching $\left(70^{\circ} \mathrm{C}, 7 \mathrm{~h}\right)$ & $8.1 \mathrm{~kJ} \cdot \mathrm{cm}^{-2}$ equivalent to Bordeaux \\
\hline 9. & Pause $(2 \mathrm{~h})$ & To avoid phosphorescence after bleach \\
\hline 10. & Preheat $\left(70^{\circ} \mathrm{C}\right.$ for $\left.900 \mathrm{~s}\right)$ & Temperature stabilization \\
\hline 11. & IR-RF $\left(70^{\circ} \mathrm{C}\right.$ for $\left.50 \mathrm{ks}\right)$ & IR-RF regenerated curve \\
\hline
\end{tabular}

"Bleaching time varies as power of each solar simulator is different for each lexsyg device. For Hannover, a fixed duration of $1500 \mathrm{~s}$ was used for bleaching.

transmission (e.g. Gusarov et al., 2005 for investigations on the radiation-induced degeneration of optical components). The Leipzig device's high average background results from only one extreme value $\left(147,691 \mathrm{cts} \cdot \mathrm{s}^{-1} \cdot \mathrm{Gy}^{-1}\right.$ of one out of three aliquots) and could be attributed to a contaminated aliquot. We observed no signal shape change with respect 


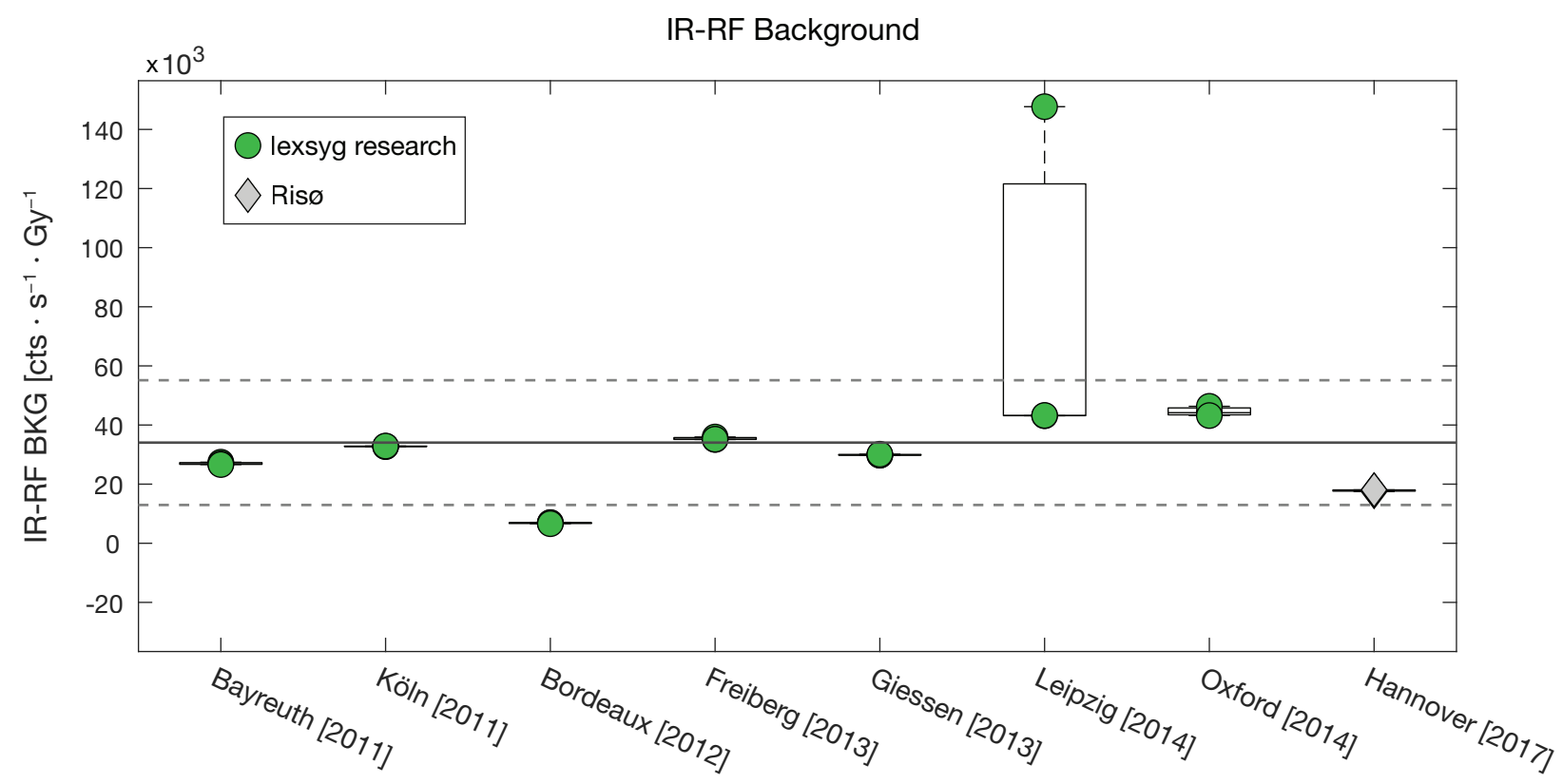

Laboratories

Fig 4. The instrumental background counts for each device are shown in boxplots. The scatter in background counts is measured for three aliquots. Background counts for each device are normalized to the device dose rate. The background levels for the lexsyg research device at Bordeaux $\left(6840 \pm 160 \mathrm{cts} \cdot \mathrm{s}^{-1} \cdot \mathrm{Gy}-1\right)$ and the Ris $\varnothing$ device at Hannover (17,858 \pm 250$)$ were on the lower side compared to the average background counts $\left(33,932 \pm 6729 \mathrm{cts} \cdot \mathrm{s}^{-1} \cdot \mathrm{Gy}-1\right.$ excluding outlier of Leipzig and lowest background of Bordeaux device). One aliquot out of three from Leipzig shows $1,47,691 \mathrm{cts} \cdot \mathrm{s}^{-1} \cdot G y^{-1}$, which is exceptionally high and can be considered an outlier. Further, the background level for the newly installed lexsyg research devices at Leipzig ( 43,000 cts $\cdot \mathrm{s}^{-1} \cdot \mathrm{Gy}{ }^{-1}$; excluding one outlier; manufactured in 2014) and Oxford $\left(\sim 45,000 \mathrm{cts} \cdot \mathrm{s}^{-1} \cdot \mathrm{Gy}^{-1} ;\right.$ manufactured in 2014) is elevated as compared to the average background. (Note: the detection method for the Ris $\varnothing$ system is different from the lexsyg research device, for more details, see main text).

to measurement time for this particular aliquot, and also, the temperature readings for each measurement remained within $70 \pm 1{ }^{\circ} \mathrm{C}$ as observed for the other aliquots. Further, the background counts for the Risø device amount to $17,858 \pm 250 \mathrm{cts} \cdot \mathrm{s}^{-1} \cdot \mathrm{Gy}^{-1}$, which is, in general, lower as compared to the lexsyg research device. The lower background counts for the Risø device is probably due to the different IR-RF measurement design (Lapp et al., 2012).

The observations on the background measurement are:

- The average background signal is 33,932 \pm $6729 \mathrm{cts} \cdot \mathrm{s}^{-1} \cdot \mathrm{Gy}^{-1}$ for lexsyg devices, except for the Bordeaux device being exceptionally low and for the Leipzig device being exceptionally high. The latter observation might be attributed to a contaminated cup.

- The background signal for the lexsyg research devices manufactured in 2014 supplied to Leipzig and Oxford are on the higher side (Leipzig $\sim 43,000 \mathrm{cts} \mathrm{s}^{-1} \cdot \mathrm{Gy}^{-1}$ excluding outlier and Oxford $\sim 45,000 \mathrm{cts} \cdot \mathrm{s}^{-1} \cdot \mathrm{Gy}^{-1}$ ) compared to the average background signal of the other five lexysg devices $\left(33,932 \pm 6729 \mathrm{cts} \cdot \mathrm{s}^{-1} \cdot \mathrm{Gy}^{-1}\right)$.

- The Risø device background signal (17,858 \pm 250 cts $\cdot \mathrm{s}^{-1} \cdot \mathrm{Gy}^{-1}$ ) was lower than the average background signal $\left(33,932 \pm 6729 \mathrm{cts} \cdot \mathrm{s}^{-1} \cdot \mathrm{Gy}^{-1}\right)$ of five lexsyg devices, attributed to the different way of signal detection.

\subsection{Naturally Bleached Sample: Modern Analogue}

A naturally bleached modern dune sand sample (Kunz et al., 2010) was used to test the IR-RF signal's bleachability. Buylaert et al. (2012) have observed an overestimation of IR-RF ages for young samples, an underestimation for older samples and modern samples (i.e., zero doses) resulting in negative dose values. These results raised doubts about the controlled bleachability of the IR-RF signal. Frouin et al. (2015) observed that IR-RF was bleachable with different SLS wavelengths, following the protocol given in Table 4. Frouin et al. (2015) showed that the SLS of the lexsyg research device with adjusted LEDs settings could achieve a bleaching plateau within 3 h (cf. Fig. 5 in Frouin et al., 2015). Further, a comparison of the bleaching with other variants of luminescence e.g. infrared stimulated luminescence (IRSL) and post infrared-infrared stimulated luminescence (post-IR-IRSL), showed that a $3 \mathrm{~h}$ bleaching with a Hönle SOL 500 lamp could reduce the IR-RF signal to its residual level (cf. Fig. 6 in Frouin et al., 2017). 

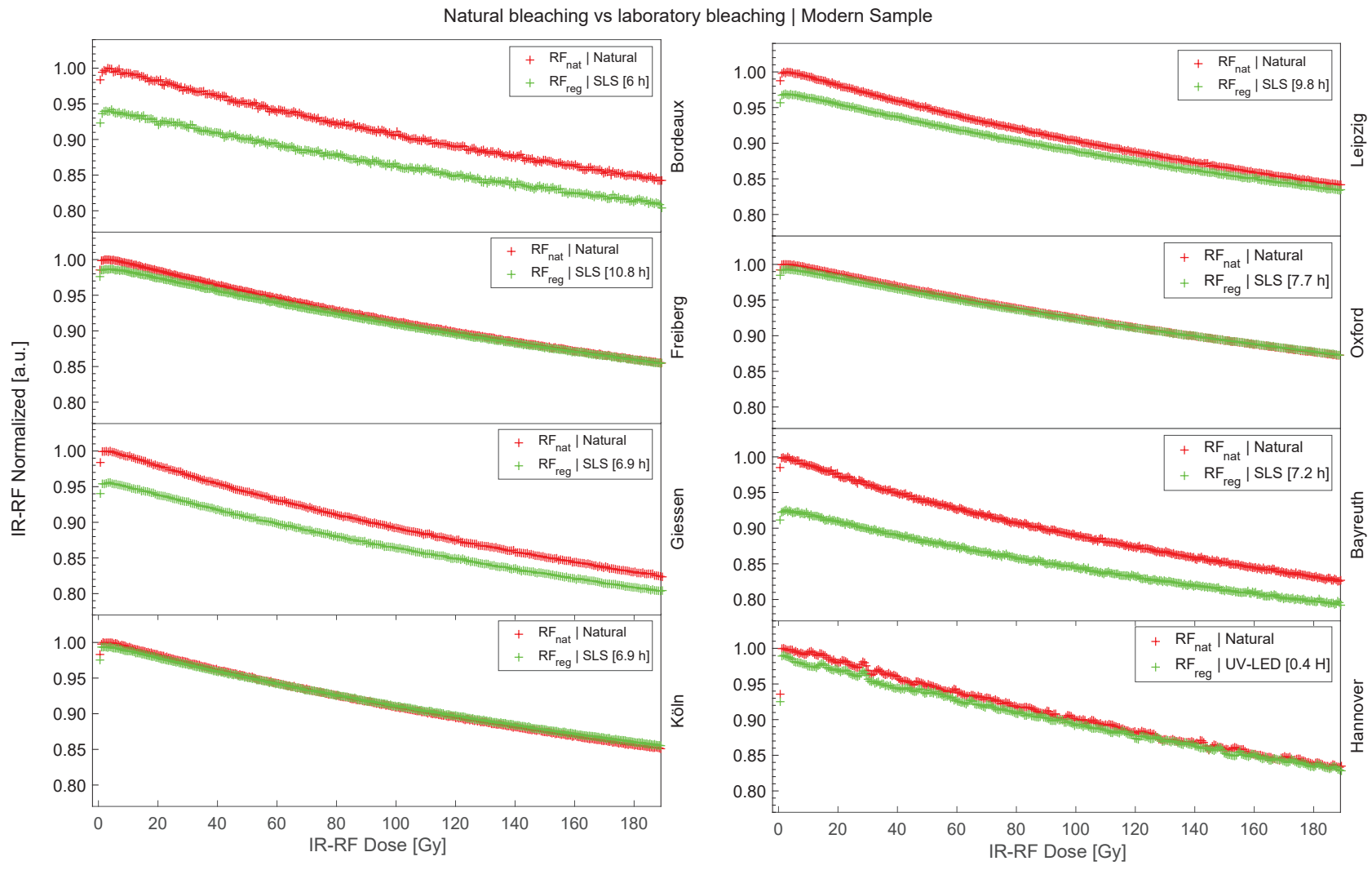

Fig 5. The behaviour of natural $\left(R F_{n a}\right)$ and regenerated $\left(R F_{r e p}\right)$ IR-RF curves for a modern sample for all devices. Most of the devices show a noticeable difference between $R F_{\text {nat }}$ and $R F_{\text {reg }} I R-R F$ signal except for those at köln and Oxford.

In order to minimize phosphorescence, a $2 \mathrm{~h}$ pause was given after each bleaching (Erfurt and Krbetschek, 2003a suggested $>1 \mathrm{~h}$ ).

In order to compare the IR-RF bleaching behaviour, the signal from the naturally bleached modern sample $\left(\mathrm{RF}_{\mathrm{nat}}\right)$ and the corresponding regenerated signal after laboratory bleaching $\left(\mathrm{RF}_{\mathrm{reg}}\right)$ were contrasted in the same plot (Fig. 5). It is demonstrated that $\mathrm{RF}_{\text {nat }}$ is higher in some cases than $\mathrm{RF}_{\text {reg }}$ and bleaching of the sample in the laboratory with the SLS (lexsyg research) or UV-LED (Risø) cannot reproduce the value of the $\mathrm{RF}_{\text {nat }}$ signal of the modern analogue sample. Except for the devices at Oxford and Köln, all devices showed a value of the $\mathrm{RF}_{\text {nat }}$ signal larger by $1-5 \%$ compared to $\mathrm{RF}_{\text {reg }}$ (Fig. 5). The offset of the high natural signal was also estimated in terms of dose value in gray using the vertical sliding method, and the scatter in dose values for the individual equipment is shown as a boxplot in Fig. 6 .

The observations on the bleachability for the modern analogue sample are:

- Except for the devices at Oxford and Köln, all the devices showed higher $\mathrm{RF}_{\text {nat }}$ than $\mathrm{RF}_{\text {reg }}$ signals even after bleaching for a $6 \mathrm{~h}$ equivalent flux recommended by Frouin et al. (2015).
- Most of the devices showed a difference between $\mathrm{RF}_{\text {nat }}$ and $\mathrm{RF}_{\text {reg }}$ up to $\sim 2 \%$. This finding implies a dose offset of $\sim 30 \mathrm{~Gy}$, except for the devices at Bordeaux and Bayreuth.

- The maximum difference between $\mathrm{RF}_{\text {nat }}$ and $\mathrm{RF}_{\text {reg }}$ was noticed for the devices at Bordeaux and Bayreuth, and the corresponding dose offset was up to $\sim 40 \mathrm{~Gy}$ and $\sim 70 \mathrm{~Gy}$, respectively.

\subsection{Saturation of IR-RF: Triassic Sandstone Sample}

The Triassic sandstone with an age of $\sim 250 \mathrm{Ma}$ (Röhling et al., 2018) was used to assess the saturation level of the IR-RF dating method. Assuming a natural dose rate of $2-2.5 \mathrm{~Gy} \cdot \mathrm{ka}^{-1}$, the sandstone sample's minimum equivalent dose should be $\sim 500 \mathrm{kGy}$. The data from all devices were analysed using the horizontal and vertical sliding method (Kreutzer et al., 2017b; Murari et al., 2018). All estimated dose values were consistent and provided an average dose of $1265 \pm 329$ Gy (median $1172 \mathrm{~Gy}$ ), with the scatter in the dataset caused by some exceptionally high dose values (Fig. 7). The sandstone sample was expected to have a much larger dose value, also because it could be shown that the laboratory-induced IR-RF decays beyond $\sim 3.3 \mathrm{kGy}\left(50,000 \mathrm{~s} ; \mathrm{RF}_{\text {reg }}\right.$ in 


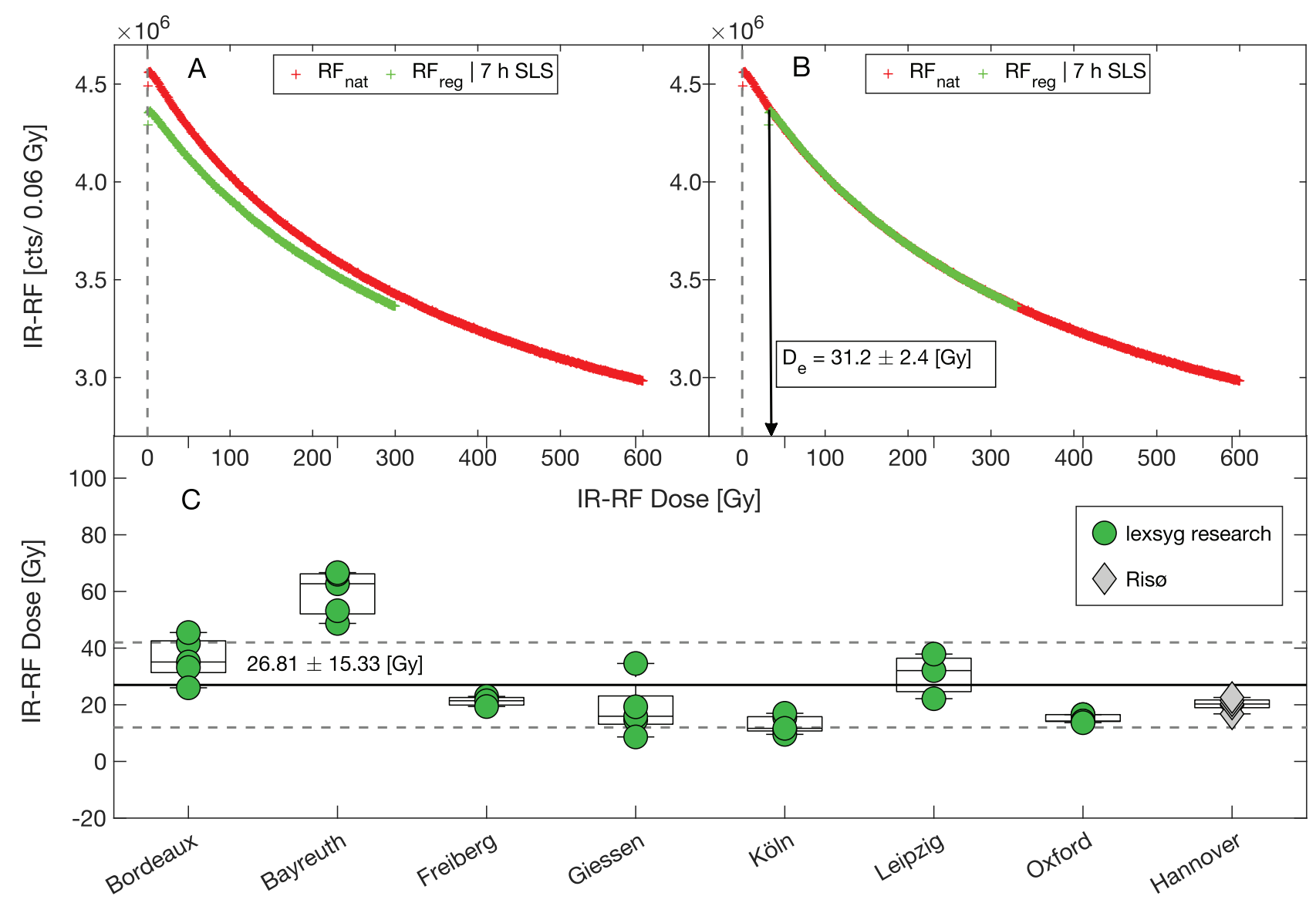

Laboratories

Fig 6. A) A typical behaviour of IR-RF signals for $R F_{\text {nat }}$ and $R F_{\text {reg }}$. B) Dose estimation by sliding the $R F_{\text {reg }}$ onto the $R F_{\text {nat }}$ signal. C) Boxplot shows the scatter in dose values for individual devices, estimated using vertical sliding of the $R F_{\text {nat }}$ signal onto the $R F_{\text {reg }}$ signal.

Fig. 2). A similar observation was made by Trautmann et al. (1999a), measuring the dose of a sediment sample from Germany (Ook1). This sample was expected to be $>2.6 \mathrm{Ma}$ old, but the authors reported an IR-RF age of $745 \pm 144 \mathrm{ka}$, which would result in an equivalent dose of $\sim 1490 \pm 288 \mathrm{~Gy}$ to $1860 \pm 360 \mathrm{~Gy}$, assuming typical natural environmental dose rate of $2-2.5 \mathrm{~Gy} \cdot \mathrm{ka}^{-1}$ (Trautmann et al.,1999a).

The major observations on the Triassic sandstone sample are:

- Determined equivalent doses range from $\sim 1000 \mathrm{~Gy}$ to $1700 \mathrm{~Gy}$, excluding the extreme dose value (2798.8 Gy) for one measurement at Freiberg.

- The measured average dose value for all laboratories for the sandstone sample with an anticipated minimum palaeodose of $\sim 500 \mathrm{kGy}$ is limited to $1265 \pm 329 \mathrm{~Gy}$. This observation is similar to the maximum IR-RF dose range $\sim 1490-1860$ Gy estimated from the IR-RF age provided by Trautman et al. (1999a).
- The average IR-RF dose value for the Risø device was $1081 \pm 117$, which was comparable to the lexsyg research device.

\subsection{IR-RF Initial Rise}

The initial rise behaviour of the IR-RF signal was first reported by Schilles (2002) and later detailed by Huot et al. (2015). Frouin et al. (2017) reported a dependency of the initial rise on the equivalent dose. Its origin is not clear but could be explained by several phenomena possibly coinciding, such as (1) a slow electron trapping rate at the beginning of the stimulation (irradiation), (2) a contribution from radiation-dependent signals other than the central IRRF peak $(865 \mathrm{~nm})$ and (3) a contribution from the shallow traps due to temperature variation during the measurement (Huot et al., 2015).

Huot et al. (2015) suggested that a rapid increase in $\mathrm{RF}$ at the beginning of the irradiation could be explained by thermally assisted phosphorescence. 'Minute variations in sample temperature' (Huot et al., 2015, p. 241) 


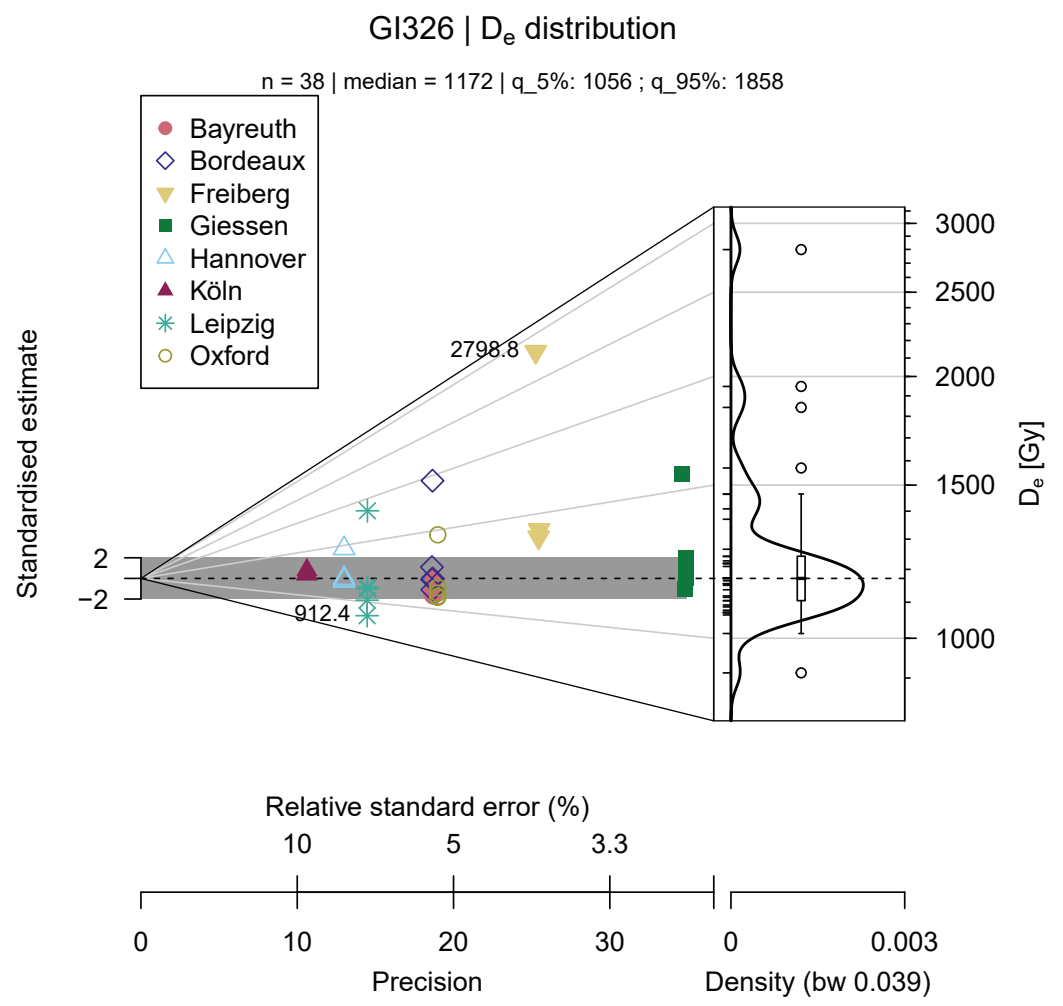

Fig 7. Dose distribution of all measurements for the Triassic sandstone sample ( $250 \mathrm{Ma}$ ). The dose value ranges from ca $1000 \mathrm{~Gy}$ to ca $1700 \mathrm{~Gy}$ for the lexsyg research devices except for one outlier (2798.8 Gy) for the device at Freiberg. The dose value for the Ris $\varnothing$ device is $1080 \pm 150 \mathrm{~Gy}$, which is also comparable to the average dose value obtained for the lexsyg research devices. The dashed line indicates the central value, here the weighted mean of the values on a log scale. The grey polygon displays the area of \pm 2 standard estimates around the central value.

can cause this peak due to shallow traps, which emit phosphorescence in the near-infrared. To avoid this peak, their recommendation was to include a pause for $>1 \mathrm{~h}$ after bleaching, enabling the sample to lose the lowtemperature signal or to measure the RF at an elevated temperature of $\sim 70{ }^{\circ} \mathrm{C}$. In this study, IR-RF was measured at $70{ }^{\circ} \mathrm{C}$ with a pause of $2 \mathrm{~h}$ after bleaching to circumvent phosphorescence. Despite these steps, the initial rise behaviour was observed for all the devices and for both samples (Fig. 8).

The observations on the initial rise behaviour from all devices are:

- Every device exhibits the initial rise at the beginning of the IR-RF signal, measured at $70{ }^{\circ} \mathrm{C}$ on a lexsyg and Risø device.

- Measurements on a Risø device showed that the first IR-RF measurement point stays lower by $\sim 6 \%$ of the maximum IR-RF point while it is limited to $\sim 3 \%$ for all lexsyg research devices.

- The IR-RF signal typically starts decreasing after $\sim 3$ Gy for the naturally bleached sample (see Table 5 for sample LUM1225). For the old sandstone sample GI326, all the devices exhibit an initial rise equivalent to $19.04 \pm 4.24 \mathrm{~Gy}$. A slightly higher initial rise equivalent to $24.4 \pm 8.9$ Gy was observed for the Bordeaux device while it was $15.8 \pm 2.3$ Gy and thus slightly lower for the Risø device.

\section{DISCUSSION}

\subsection{Why is the $\mathrm{RF}_{\text {nat }}$ Signal Elevated for the Naturally Bleached Sample?}

The naturally bleached modern analogue sample shows an $\mathrm{RF}_{\text {nat }}$ signal $>\mathrm{RF}_{\text {reg }}$. The difference between $\mathrm{RF}_{\text {nat }}$ and $\mathrm{RF}_{\text {reg }}$ was equivalent to a dose offset of $\sim 20 \mathrm{~Gy}$. The reasons could be (1) a loss of grains from the aliquots, (2) a geometry change of the sample in relation to the detection unit (Erfurt and Krbetschek, 2003a) and (3) a change in sensitivity of the sample due to laboratory bleaching, irradiation or a combination of both factors; or (4) simply that sunlight bleaching is more effective than the SLS and UV bleaching, except for the Oxford and Köln devices (Table 5). 


\section{IR-RF Initial rise | Gl326}

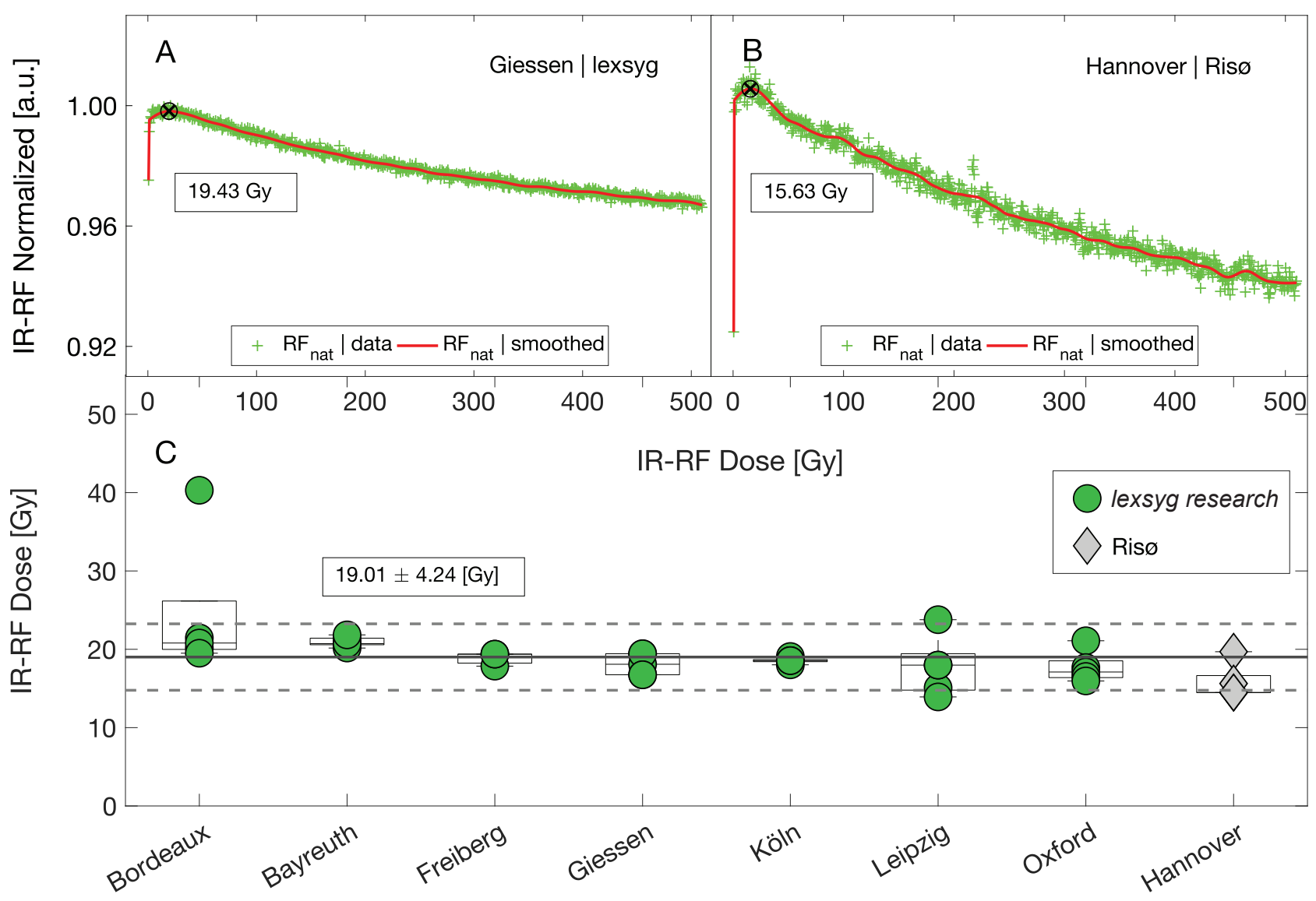

Fig 8. A) and B) A typical behaviour of Initial rise for IR-RF measurements on Triassic sandstone sample GI326. IR-RF data was normalized to its maximum IR-RF value and smoothed. Every device showed an initial rise in the signal before decaying monotonically. An equivalent dose corresponding to the initial rise point was approximated from the smoothed data as there was a significant amount of noise in the original data. C) Boxplot shows the scatter in estimated dose values for individual devices for 5 aliquots (except Freiberg which has 3 aliquots). The average value of dose for initial rise was equivalent to $19.01 \pm 4.24 \mathrm{~Gy}$, and it was slightly lower (15.8 $\pm 2.3 \mathrm{~Gy}$ ) for the Ris $\varnothing$ device. Further, the first IR-RF point for all lexsyg research devices stays at $\sim 3 \%$ lower than its maximum IR-RF point while it was $\sim 6 \%$ for the Ris $\varnothing$ device.

Loss of grains: To exclude grain loss as a cause, an additional experiment was conducted by mounting the sample using aluminium tape as an adhesive. IR-RF measurements with the lexsyg research device at Giessen using conventional sample mounting showed $\sim 1-4 \%$ change in signal. The same values were observed for the aluminium-tape mounted sample, while the $\mathrm{RF}_{\text {nat }}$ signal was still higher than the $\mathrm{RF}_{\text {reg. }}$. This implies that loss of grains is not responsible for the observation $\mathrm{RF}_{\text {nat }}>>\mathrm{RF}_{\text {reg }}$ signal (Fig. 9).

Change of geometry: Erfurt and Krbetschek (2003a) emphasised that the sample geometry during measurement must be maintained. In this study, a sample cup was marked for testing this, and its position was recorded on the lexsyg research device at Giessen. However, although a slight rotation occurred during the sample cup movement between measurement and bleaching position, multiple measurements of the $\mathrm{RF}_{\text {reg }}$ signal after bleaching did not show any significant change (Fig. 10). This experiment confirms that, despite having a change in rotation, it does not significantly affect the signal and cannot explain the high levels of $\mathrm{RF}_{\text {nat }}$.

Sensitivity change or incomplete bleaching: IRSL sensitivity change for feldspar upon light exposure has been reported in the past, and Li and Wintle (1992) observed a sensitivity decrease of $27 \%$ for colluvial samples bleached with a SLS. Further, Richardson (1994) has reported that light exposure does not affect the sensitivity, but heating at $450{ }^{\circ} \mathrm{C}$ showed a significant decrease in sensitivity. Similar observations were noticed for the IR-RF measurements in this study (Fig. 5). In most cases, $\mathrm{RF}_{\text {nat }}$ is higher than $\mathrm{RF}_{\text {reg, }}$ except for the Oxford and Köln devices, but multiple cycles of SLS bleaching inside the lexsyg research device could reproduce $R_{\text {reg }}$ intensities without significant difference (Fig. 10). However, unlike conventional feldspar luminescence, the IR-RF signal is believed to be a direct measure of the fraction of empty electron traps, and sensitivity change might relate to different mechanisms. For 
Table 5. The observations made on all devices for background, initial rise, bleaching of the modern analog dune sand sample LUM1225 and the sandstone sample G1326 which was 250 Ma old.

\begin{tabular}{|c|c|c|c|c|c|c|c|c|c|c|c|}
\hline \multirow{3}{*}{$\begin{array}{l}\text { Labs } \\
\text { Bordeaux }\end{array}$} & \multirow{3}{*}{$\begin{array}{l}\text { Device } \\
\text { [manufacturing year] } \\
\text { Lexsyg [2012] }\end{array}$} & & & \multicolumn{3}{|c|}{ "\#Initial rise IR-RF dose [Gy] } & \multicolumn{3}{|c|}{ Modern sample [LUM1225] } & \multirow{2}{*}{\multicolumn{2}{|c|}{$\begin{array}{l}\text { Old sample [GI326] } \\
\text { IR-RF Dose [Gy] }\end{array}$}} \\
\hline & & \multicolumn{2}{|c|}{$\begin{array}{l}\text { +Background } \\
{\left[\text { cts } \cdot \mathrm{s}^{-1} \cdot \mathrm{Gy}^{-1} \text { ] }\right.}\end{array}$} & \multirow{2}{*}{$\begin{array}{c}\frac{\mathrm{RF}_{\mathrm{reg}}}{[0 \mathrm{~Gy}]} \\
3.1 \pm 0.5\end{array}$} & \multirow{2}{*}{$\begin{array}{c}\begin{array}{c}\mathbf{R F}_{\text {nat }} \\
{[\sim 1200 \mathrm{~Gy}]}\end{array} \\
24.4 \pm 8.9\end{array}$} & \multirow[b]{2}{*}{$(n=5)$} & \multirow{2}{*}{$\begin{array}{c}\begin{array}{c}\Delta \text { IR-RF } \\
{[\%]}\end{array} \\
4.2 \pm 1.5\end{array}$} & \multicolumn{2}{|c|}{$\begin{array}{l}\text { "Equivalent IR-RF } \\
\text { dose [Gy] }\end{array}$} & & \\
\hline & & $6840 \pm 160$ & $(n=3)$ & & & & & $36.3 \pm 7.6$ & $(n=5)$ & $1539 \pm 438$ & $(n=5)$ \\
\hline Bayreuth & Lexsyg [2011] & $26627 \pm 406$ & $(n=3)$ & $3.5 \pm 1.4$ & $20.9 \pm 0.6$ & $(n=5)$ & $5.1 \pm 1.7$ & $59.5 \pm 8.1$ & $(n=5)$ & $1115 \pm 49$ & $(n=5)$ \\
\hline Freiberg & Lexsyg [2013] & $35417 \pm 456$ & $(n=3)$ & $3.2 \pm 0.8$ & $18.9 \pm 0.9$ & $(n=3)$ & $0.8 \pm 0.5$ & $21.3 \pm 1.8$ & $(n=3)$ & $1599 \pm 591$ & $(n=6)$ \\
\hline Giessen & Lexsyg [2013] & $29912 \pm 183$ & $(n=3)$ & $2.9 \pm 0.4$ & $18.1 \pm 1.3$ & $(n=5)$ & $1.3 \pm 1.8$ & 18.6 & $(n=5)$ & $1259 \pm 179$ & $(n=5)$ \\
\hline Köln & Lexsyg [2011] & $32788 \pm 91$ & $(n=3)$ & $2.9 \pm 0.3$ & $18.6 \pm 0.4$ & $(n=5)$ & $0.2 \pm 0.4$ & $12.9 \pm 3.1$ & $(n=5)$ & $1234 \pm 30$ & $(n=5)$ \\
\hline Leipzig++ $^{++}$ & Lexsyg [2014] & $43185 \pm 62$ & $(n=2)$ & $2.9 \pm 0.3$ & $17.8 \pm 3.8$ & $(n=5)$ & $2.2 \pm 1.3$ & $30.7 \pm 7.9$ & $(n=5)$ & $1199 \pm 383$ & $(n=5)$ \\
\hline Oxford & Lexsyg [2014] & $44567 \pm 1598$ & $(n=3)$ & $3.0 \pm 0.3$ & $17.7 \pm 2.0$ & $(n=5)$ & $0.1 \pm 0.5$ & $15.1 \pm 1.4$ & $(n=5)$ & $1163 \pm 176$ & $(n=5)$ \\
\hline Hannover & $\operatorname{Risø~[2017]~}$ & $17858 \pm 306$ & $(n=3)$ & $2.6 \pm 0.5$ & $15.8 \pm 2.3$ & $(n=5)$ & $1.3 \pm 0.6$ & $20.2 \pm 2.2$ & $(n=5)$ & $1081 \pm 117$ & $(n=5)$ \\
\hline
\end{tabular}

+Background: All devices have different dose rates, therefore background counts per second were normalized to the dose rate of each device. ${ }^{++}$Leipzig background values were estimated without the outlier aliquot, which had background counts of $\sim 147,691 \mathrm{cts} \cdot \mathrm{s}^{-1} \cdot \mathrm{Gy}^{-1}$.

${ }^{*} \Delta \mathrm{IR}-\mathrm{RF}$ : The percentage change between the $\mathrm{RF}_{\text {nat }}$ and $\mathrm{RF}_{\text {reg }}$ was estimated from the maximum value of IR-RF signal and the uncertainty is the standard deviation of the aliquots used for the measurement.

"Equivalent IR-RF dose: An estimation of offset in terms of dose using the vertical slide method, but $R F_{\text {reg }}$ was slided on $R F_{\text {nat }}$ as $R F_{\text {nat }}>R F_{\text {reg }}$. \#\#Initial rise IR-RF dose: The dose value equivalent to the initial rise was estimated using the maximum of the IR-RF signal where the signal starts to decay normally. Estimation of maximum IR-RF point was approximated by smoothing IR-RF data. It was estimated for both samples, LUM1225 modern analogue (bleached) sample and GI326 old sandstone (saturated) sample.

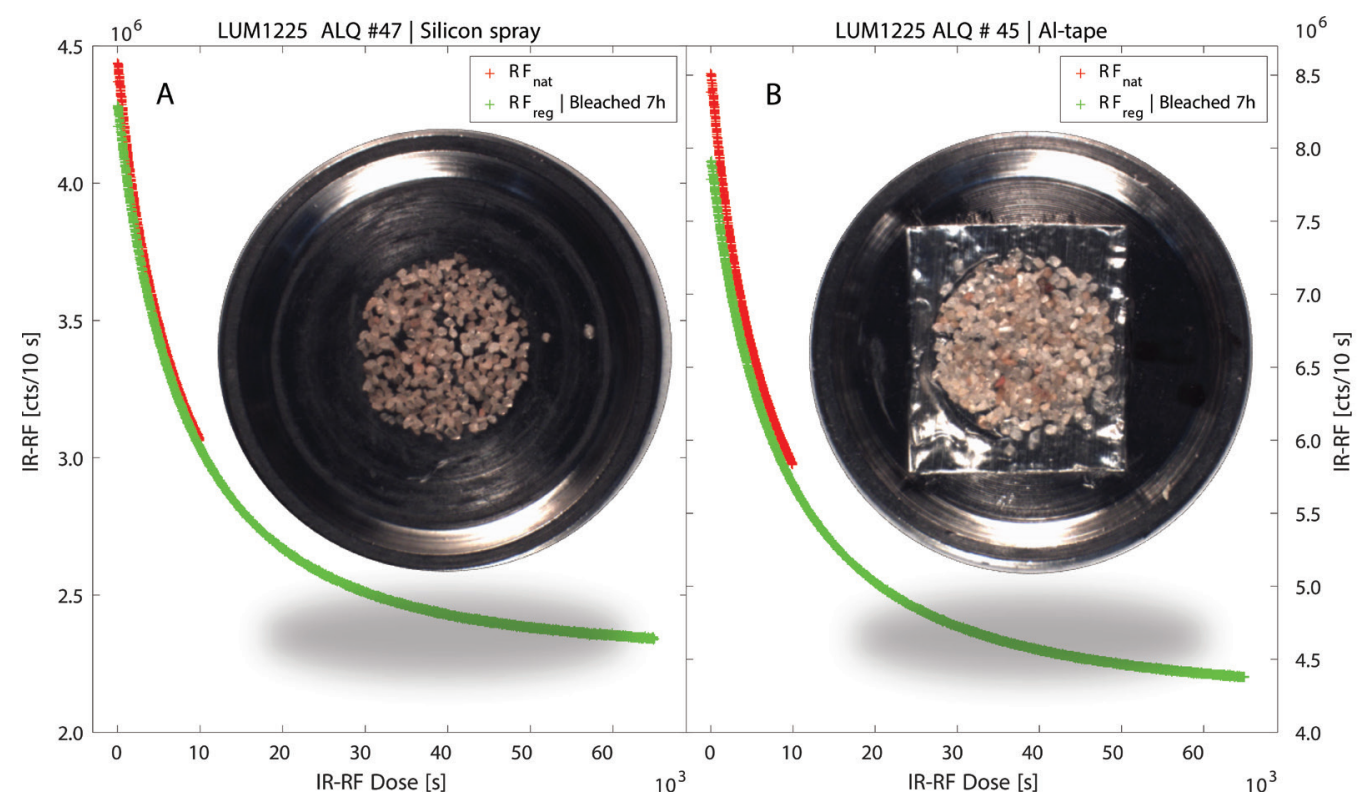

Fig 9. A) IR-RF signal from the modern analog sample LUM1225, mounted with silicon oil on the cups. B) IR-RF signal when the same sample is mounted with aluminum adhesive tape (Tesa company), heat resistant up to $140^{\circ} \mathrm{C}$. The Al tape prevents grain loss or further lateral dispersion of grains on the sample carrier during the measurement. However, the $R F_{\text {nat }}$ intensity is always higher than $R F_{\text {reg }}$ for both cases.

instance, IRSL or TL involve complex transition pathways between traps and recombination centres (TL; cf. Aitken, 1985; IRSL; Hütt et al., 1988).

An $\mathrm{RF}_{\text {nat }}$ signal of higher intensity than the $\mathrm{RF}_{\text {reg }}$ signal may imply that natural sunlight is more effective in optical signal resetting than SLS bleaching and that after laboratory bleaching, a residual signal remains. However, the reproducibility of $\mathrm{RF}_{\text {reg }}$ intensities suggests that the same level of bleaching can be achieved repeatedly with the built-in SLS of the device (Fig. 10). Furthermore, previous experiments confirmed that complete bleaching could be achieved from a fraction of an hour to a few hours, e.g. 30 min using a 


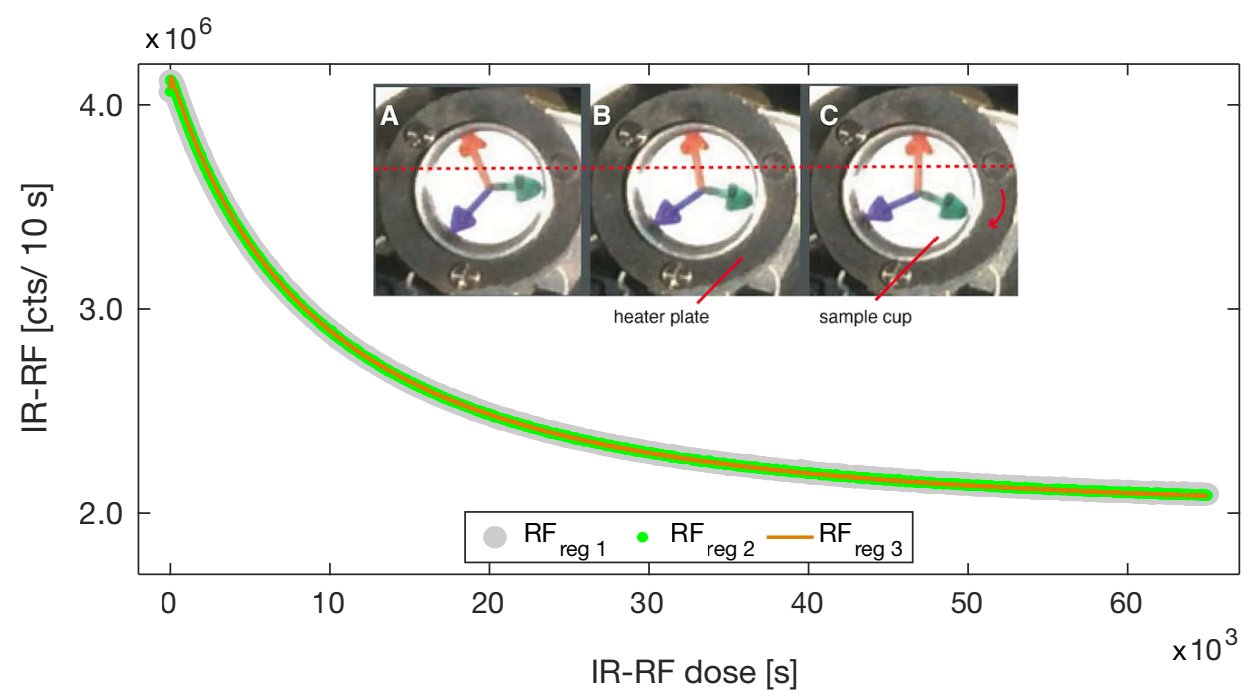

Fig 10. A series of photos from A to C showing the change in sample geometry. A sticker was placed in a sample cup with markings of three arrows. The arrows' different positions clearly show the movement of the cup when the arm moves from one position to another. The IR-RF curves blue, yellow, and red are the repeated measurements of $R F_{\text {reg }}$ of the same aliquot. The sample was bleached for $7 \mathrm{~h}$ with the solar simulator followed by a pause of $2 \mathrm{~h}$ before measurement of $R F_{\text {reg. }}$. All three repeated regenerated $R F_{\text {reg }}$ curves do not show any significant change in shape and intensity. The overlapping three repeated $R F_{r e g}^{r e g}$ curves confirm that the rotation geometry change has no significant effect on the IR-RF signal.

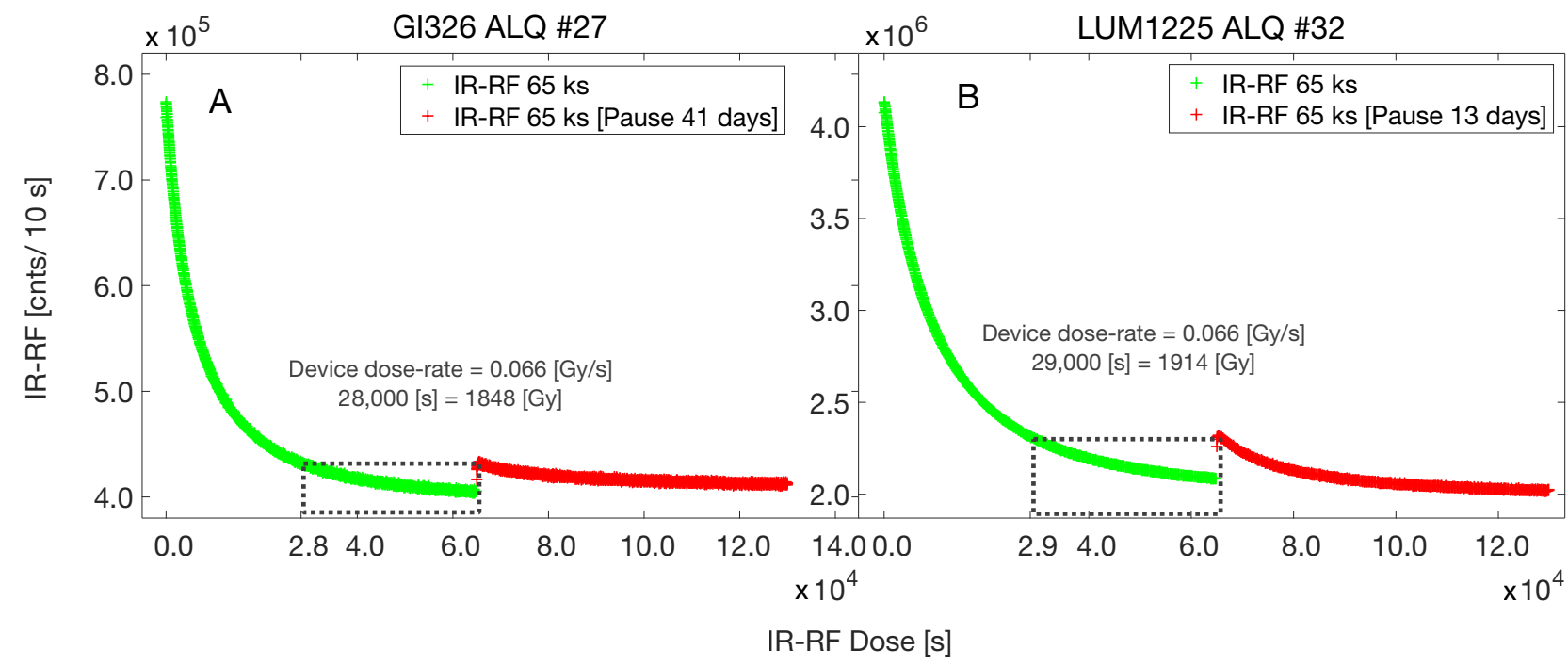

Fig 11. Early saturation of the geological sample. A) and B) show two measurements of IR-RF before and after a pause. Green-coloured IR-RF for a dose equivalent to 4,290 Gy is recorded just after bleaching of the sample for $7 \mathrm{~h}$, and red-coloured IR-RF is recorded after the pause of several days. The units of the $y$-axes are similar for both figures.

$250 \mathrm{~W}$ OSRAM metal halide (Krbetschek et al., 2000), $25 \mathrm{~min}$ using a $700 \mathrm{~mW} \mathrm{~cm}^{-2}$ UV-LED, $\sim 4 \mathrm{~h}$ using a Hönle SOL 2 SLS (Buylaert et al., 2012) and $3 \mathrm{~h}$ using an SLS in lexsyg research devices (Frouin et al., 2015, 2017). If we assume complete optical RF signal resetting, another possible cause for $\mathrm{RF}_{\text {nat }}>>\mathrm{RF}_{\text {reg }}$ signal could be the sensitivity change due to laboratory treatments (bleaching or irradiation or due to both). Schilles and Habermann (2000), Erfurt and Krbetschek (2003a), Varma et al. (2013) and Murari et al. (2018) have observed IR-RF sensitivity changes in their studies. Erfurt and Krbetschek (2003a) found that it may lead to an equivalent dose deviation of $\sim 3 \%$.

\subsection{Why do we Observe Early Saturation for Old Samples?} Shallow traps: The observations on the saturated sample suggest that the IR-RF dose value $(1265 \pm 329$ Gy) determined is significantly underestimated for the sandstone sample from Bayreuth, Germany, which is of Triassic age 
( $250 \mathrm{Ma})$. Therefore, this sample should have a minimum $D_{\mathrm{e}}$ of $\sim 500 \mathrm{kGy}$ assuming a minimum natural effective dose rate of $2 \mathrm{~Gy} \cdot \mathrm{ka}^{-1}$. One of the possible underlying reasons is the participation of shallow traps in IR-RF signal production. Since IR-RF is measured directly under continuous radiation stimulation, shallow traps also contribute to the signal and drain their charge when the sample is cut off from the radiation. Hence, one experiment was designed to detect the potential effect of shallow traps: both samples were first bleached with the SLS for $7 \mathrm{~h}$. IR-RF was measured for $65 \mathrm{ks}(4.29 \mathrm{kGy})$ and then measured again for the same duration (dose) after a pause of a few days. This preliminary examination shows that a given dose of 4290 Gy resulted in a $D_{\mathrm{e}}$ of $\sim 1900$ Gy after 13 days and 41 days of pause. This experiment suggests that the IR-RF signal for these samples approaches saturation earlier than the given dose of $\sim 4290$ Gy (Fig. 11) and indicates a kind of signal loss for large doses. However, further experiments will be required to establish its characteristics and determine the typical saturation dose.

\section{CONCLUSIONS}

The interlaboratory comparison carried out on eight IR-RF systems suggests the following:

- The instrumental background for all devices is $33,932 \pm$ $6729 \mathrm{cts} \cdot \mathrm{s}^{-1} \cdot \mathrm{Gy}^{-1}$, except the device from Bordeaux, which yields $6840 \pm 160 \mathrm{cts} \cdot \mathrm{s}^{-1} \cdot \mathrm{Gy}^{-1}$. The background of $\sim 45,000 \mathrm{cts} \cdot \mathrm{s}^{-1} \cdot \mathrm{Gy}^{-1}$ and $\sim 43,000 \mathrm{cts} \cdot \mathrm{s}^{-1} \cdot \mathrm{Gy}^{-1}$ is higher for the newly manufactured lexsyg research at Oxford (in 2014) and Leipzig (in 2014), while it is lower for the Risø device $\left(\sim 17,853 \mathrm{cts} \cdot \mathrm{s}^{-1} \cdot \mathrm{Gy}^{-1}\right)$, likely due to the difference in signal detection conditions. As expected, background levels are higher than other variants of luminescence (e.g., OSL or IRSL) since signal detection takes place close to the beta source.

- For the naturally bleached sample, $\mathrm{RF}_{\text {nat }}>\mathrm{RF}_{\text {reg }}$ in all systems, except for the Oxford and Köln devices, which show significantly lower differences. The signal difference for most devices equates to an average dose offset of $\sim 26.8 \mathrm{~Gy}$, except for the devices at Bordeaux and Bayreuth, showing offsets of up to $\sim 40 \mathrm{~Gy}$ and $\sim 70$ Gy, respectively.
- Loss of grains and/or a change in the geometry during multiple measurements do not explain the higher $\mathrm{RF}_{\text {nat }}$ in comparison to $\mathrm{RF}_{\text {reg }}$. It is concluded that the sensitivity changes due to laboratory procedures, which may cause such differences. However, the devices at Oxford and Köln do not show this change, and the reason for it is unclear.

- As determined for the Triassic sandstone sample $(\sim 250 \mathrm{Ma})$, the saturation dose is in the range of $1265 \pm 329$ Gy. This is far lower than the expected minimum dose of $\sim 500 \mathrm{kGy}$ for this particular sample.

- Preliminary examination of shallow traps showed that after giving a laboratory dose of $4290 \mathrm{~Gy}$, the dose determined with IR-RF amounts to $\sim 1900$ Gy after a few days of storage. This finding needs a more detailed investigation.

- Every device exhibits an initial rise even after measurement at an elevated temperature of $70^{\circ} \mathrm{C}$. It corresponds to an average dose of 19.01 \pm 4.24 Gy for all the devices for the older sample GI326. The device at Bordeaux $(24.4 \pm 8.9 \mathrm{~Gy})$ is on a slightly higher side while the Risø device ranges a little bit lower $(15.8 \pm 2.3 \mathrm{~Gy})$ than the average. However, the initial rise is limited to $\sim 3 \mathrm{~Gy}$ for all the devices for the modern sample LUM1225.

\section{ACKNOWLEDGMENTS}

M.K. Murari is financially supported by German Research Foundation (DFG FU 417/19-1) and Ministry of Earth Science [MoES/P.O.(Seismic) 8(09)-Geochron/2012] and M. Fuchs got support from German Research Foundation (DFG FU 417/19-1). S. Kreutzer received financial support from the LaScArBx. LaScArBx is a research programme supported by the ANR (ANR-10-LABX-52). M. Frouin acknowledges support by the John Fell Fund (Oxford University). N. Klasen received financial support from the Deutsche Forschungsgemeinschaft (DFG, German Research Foundation) - Projektnummer 57444011 SFB 806. We are thankful to Yannick Lefrais (IRAMATCRP2A, Bordeaux) for the SEM measurements. We thank Prof. A. K. Singhvi for providing his constructive suggestions to improve this manuscript. T. Wolpert and T. Kolb are thanked for their support in preparing some of the figures. Finally, M. K. Murari acknowledges the Geochronology group, Inter-University Accelerator Centre, for granting permission to work on this manuscript.

\section{REFERENCES}

Aitken MJ, 1985. Thermoluminescence dating. Academic Press, London.

Aitken MJ, 1998. An introduction to Optical dating: The Dating of Quaternary Sediments by the Use of Photon-stimulated Luminescence. Oxford University press, Oxford.
Buylaert JP, Jain M, Murray AS, Thomsen KJ, Lapp T, 2012. IR-RF dating of sand-sized K-feldspar extracts: A test of accuracy. $R a-$ diation Measurements 47(9): 759-765.

Erfurt G, 2003a. Infrared luminescence of $\mathrm{Pb}+$ centres in potassium-rich feldspars. Physica Status Solidi (a) 200(2): 429-438. 
Erfurt G, 2003b. Radiolumineszenzspektroskopie und -dosimetrie an Feldspaten und synthetischen Luminophoren fur die geochronometrische Anwendung (Radioluminescence spectroscopy and dosimetry on feldspars and synthetic phosphors for geochronometry). Ph.D Thesis, Technische Universität Bergakademie Freiberg, Germany.

Erfurt G, Krbetschek MR, 2003a. IRSAR-A single-aliquot regenerative-dose dating protocol applied to the infrared radiofluorescence (IR-RF) of coarse-grain K feldspar. Ancient TL 21(1): $35-42$.

Erfurt G, Krbetschek MR, 2003b. Studies on the physics of the infrared radioluminescence of potassium feldspar and on the methodology of its application to sediment dating. Radiation Measurements 37(4-5): 505-510.

Frouin $M$, Huot S, Kreutzer S, Lahaye C, Lamothe M, Philippe A, Mercier N, 2017. An improved radiofluorescence single-aliquot regenerative dose protocol for K-feldspars. Quaternary Geochronology 38: 13-24.

Frouin M, Huot S, Mercier N, Lahaye C, Lamothe M, 2015. The issue of laboratory bleaching in the infrared-radiofluorescence dating method. Radiation Measurements 81: 212-217.

Gusarov A, Doyle D, Glebov L, Berghmans F, 2005. Comparison of radiation-induced transmission degradation of borosilicate crown optical glass from four different manufacturers, In: Taylor EW eds., Presented at the Optics \& Photonics 2005, SPIE, 58970I-8. Doi 10.1117/12.619199.

Herman F, Rhodes EJ, Braun J, Heiniger L, 2010. Uniform erosion rates and relief amplitude during glacial cycles in the Southern Alps of New Zealand, as revealed from OSL-thermochronology. Earth and Planetary Science Letters 297(1-2): 183-189, DOI 10.1016/j.epsl.2010.06.019.

Huot S, Frouin M, Lamothe M, 2015. Evidence of shallow TL peak contributions in infrared radiofluorescence. Radiation Measurements 81: 237-241.

Hütt G, Jaek I, Tchonka J, 1988. Optical dating: K-Feldspars optical response stimulation spectra. Quaternity Science Reviews 7(3-4): 381-385. DOI 10.1016/0277-3791 (88)90033-9.

Krbetschek MR, Trautmann T, Dietrich A, Stolz W, 2000. Radioluminescence dating of sediments: Methodological aspects. Radiation Measurements 32(5-6): 493-498.

Kreutzer S, Schmidt C, Fuchs MC, Dietze M, Fischer M, Fuchs M, 2012. Introducing an $R$ package for luminescence dating analysis. Ancient TL 30(1): 1-8.

Kreutzer S, Dietze M, Burow C, Fuchs MC, Schmidt C, Fischer M, Friedrich J, 2017a. Luminescence: Comprehensive Luminescence Dating Data Analysis. R package version 0.7.5. https:// cran.r-project.org/package=Luminescence.

Kreutzer S, Murari MK, Frouin M, Fuchs M, Mercier N, 2017b. Always remain suspicious: A case study on tracking down a technical artefact while measuring IR-RF. Ancient TL 35(1): 20-30.
Kreutzer S, Martin L, Dubernet S, Mercier N, 2018. The IR-RF alpha-Efficiency of K-feldspar. Radiation Measurements 120: 148-156. DOI 10.1016/j.radmeas.2018.04.019.

Kunz A, Frechen M, Ramesh R, Urban B, 2010. Luminescence dating of late Holocene dunes showing remnants of early settlement in Cuddalore and evidence of monsoon activity in south east India. Quaternary International 222(1-2): 194-208.

Li SH, Wintle AG, 1992. Luminescence sensitivity change due to bleaching of sediments. Nuclear Tracks and Radiation Measurements 20(4): 567-573.

Lapp T, Jain M, Thomsen KJ, Murray AS, Buylaert JP, 2012. New luminescence measurement facilities in retrospective dosimetry. Radiation Measurements 47(9): 803-808.

Murari MK, Kreutzer S, Fuchs M, 2018. Further investigations on IR-RF: Dose recovery and correction. Radiation Measurements 120: 110-119. DOI 10.1016/j.radmeas.2018.04.017.

Murari MK, Kreutzer S, King G, Frouin M, Tsukamoto S, Schmidt C, Lauer T, Klasen N, Richter D, Friedrich J, Mercier N, Fuchs M, 2021. Infrared radiofluorescence (IR-RF) dating: A review. Quaternary Geochronology 64: 101155. DOI 10.1016/j.quageo.2021.101155.

Nesbitt HW, Young GM, 1984. Prediction of some weathering trends of plutonic and volcanic rocks based on thermodynamic and kinetic considerations. Geochimica et Cosmochimica Acta 48(7): 1523-1534.

Preusser F, Degering D, Fuchs M, Hilgers A, Kadereit A, Klasen N, Krbetschek MR, Richter A, Spencer JQ, 2008. Luminescence dating: basics, methods and applications. Quaternary Science Journal 57(1/2): 95-149.

R Core Team, 2021. R: A Language and Environment for Statistical Computing. R Foundation for Statistical Computing, Vienna, Austria. https://www.r-project.org/.

Richardson CA, 1994. Effect of bleaching on the sensitivity to dose of the infrared-stimulated luminescence of potassiumrich feldspars from Ynyslas, Wales. Radiation Measurements 27(2-3): 587-592.

Richter D, Pintaske R, Dornich K, Krbetschek MR, 2012. A novel beta source design for uniform irradiation in dosimetric applications. Ancient TL 30(2): 57-63.

Richter A, Dornich K, 2013. Lexsyg - A new system for luminescence research. Geochronometria 40(4): 220-228.

Röhling HG, Lepper J, Diehl M, Dittrich D, Freudenberger W, Friedlein V, Hug-Diegel N, Nitsch E, 2018. The buntsandstein group in the stratigraphic table of germany 2016. Zeitschrift der Dtsch. Gesellschaft fur Geowissenschaften 169: 151-180.

Schilles T, 2002. Die Infrarot-Radiolumineszenz von Feldspäten und ihr Einsatz in der Lumineszenzdatierung. Ph.D Thesis, Universität Heidelberg.

Schilles T, Habermann J, 2000. Radioluminescence dating: The IR emission of feldspar. Radiation Measurements 32(5-6): 679-683. 
Tesa Company (2020). Tesa aluminum adhesive tape/self-adhesive aluminum tape for repairs of metallic surface.WEB site: https://www.tesa.com/en/industry/general-applications/ sealing-tapes/aluminum-foil-tapes. Accessed 2020 August 31.

Thorlabs (2020): ND10B - Unmounted Reflective $\varnothing 25 \mathrm{~mm}$ ND Filter, Optical Density: 1.0. WEB site: https://www.thorlabs. com/thorproduct.cfm?partnumber=ND10B. Accessed 2020 August 31.

Trautmann T, Krbetschek MR, Dietrich A, Stolz W, 1998. Investigations of feldspar radioluminescence: Potential for a new dating technique. Radiation Measurements 29(3-4): 421-425.

Trautmann T, Krbetschek MR, Dietrich A, Stolz W, 1999a. Feldspar radioluminescence: $A$ new dating method and its physical background. Journal of Luminescence 85(1-3): 45-58.

Trautmann T, Dietrich A, Stolz W, Krbetschek MR, 1999b. Radioluminescence dating: A new tool for quaternary geology and archaeology. Naturwissenschaften 86(9): 441-444. DOI 10.1007/s001140050649.

Trautmann T, 2000. A study of radioluminescence kinetics of natural feldspar dosimeters: Experiments and simulations. Journal of Physics D 33(18): 2304-2310. DOI 10.1088/00223727/33/18/315.

Varma V, Biswas RH, Singhvi AK, 2013. Aspects of infrared radioluminescence dosimetry in K-feldspar. Geochronometria 40(4): 266-273. 